\title{
Impacto da formulação de composições granulométricas nas propriedades mecânicas e funcionais de misturas asfálticas densas
}

\author{
Impact of the formulation of aggregate gradations \\ on the mechanical and functional properties of dense asphalt mixes
}

\author{
Viviane Dias Andrade ${ }^{1}$, Breno Salgado Barra ${ }^{1}$, Liedi Bernucci ${ }^{2}$ \\ Leto Momm ${ }^{1}$, Yader Guerrero Pérez ${ }^{1}$, Daniel Hastenpflug ${ }^{1}$ \\ Helena Nierwinski ${ }^{1}$, Marcelo Heidemann ${ }^{1}$
}

\footnotetext{
${ }^{1}$ Universidade Federal de Santa Catarina (UFSC), Rua Dona Francisca, 8300, Bloco U, Zona Industrial Norte, CEP: 89.219-600, Joinville, SC, Brasil.

${ }^{2}$ Escola Politécnica da Universidade de São Paulo (EPUSP), Av. Prof. Almeida Prado, Travessa II, n. 83, CEP: 05508070, Cidade Universitária, Butantã, SP, Brasil.

e-mail: vivianeeaf@yahoo.com.br, breno.barra@ufsc.br, liedi@usp.br, daniel.h@ufsc.br, yagcivil@gmail.com, helena.paula@ufsc.br, marcelo.heidemann@ufsc.br
}

\section{RESUMO}

O objetivo principal deste trabalho é avaliar o impacto da formulação de diferentes composições granulométricas nas propriedades mecânicas e funcionais de misturas asfálticas densas, a partir dos métodos denominados tentativa, teórico e controlado. O primeiro é especificado pelos órgãos rodoviários oficiais brasileiros para a produção de misturas asfálticas, em que o objetivo é enquadrar as curvas granulométricas formuladas em faixas limítrofes estabelecidas nas diretrizes normativas. Quanto ao método teórico, também denominado racional, compreende a seleção discretizada dos diâmetros de partículas, permitindo assim controlar com precisão a distribuição dos percentuais granulares, dispensando o uso de faixas granulométricas, a partir das equações de Füller-Talbot. O método controlado trata-se de uma adaptação realizada nesta pesquisa, em que foi procedido o fracionamento individual das partículas granulares previstas na formulação por tentativa, porém, respeitando a mesma série de peneiras e os percentuais de distribuição originalmente adotados. Para tanto, foram caracterizados e utilizados granulares de origem gnáissica provenientes de jazida localizada na região metropolitana de Joinville/SC, bem como o ligante asfáltico de classificação por penetração 50/70 $(0,1 \mathrm{~mm})$ fornecido por refinaria localizada em Paulínia/SP. Foram testadas as propriedades mecânicas de habilidade de compactação com a prensa de compactação por cisalhamento giratório (PCG), resistência à ação deletéria da água no ensaio de Duriez a $18^{\circ} \mathrm{C}$, e resistência à deformação permanente, enquanto as propriedades funcionais como macrotextura e tempo de escoamento superficial da água foram avaliadas pelos ensaios de altura de mancha de areia e drenabilidade. Os resultados obtidos indicam que o método de formulação teórico é mais eficiente que os demais estudados, em razão de apresentar os melhores indicadores mecânicos e funcionais em todos os parâmetros avaliados, e que o método por tentativa demonstrou ser o mais precário tecnicamente, devendo ser substituído por uma metodologia mais científica e acurada no Brasil.

Palavras-chave: Composições granulométricas; Misturas asfálticas densas; Métodos de formulação; Propriedades mecânicas; Propriedades funcionais.

\section{ABSTRACT}

The main aim of this manuscript is to evaluate the impact of the formulation of aggregate gradations on the mechanical and functional properties of dense asphalt mixes, comprising methodologies so-called by trial, theoretical and controlled. The first is standardized by Brazilian official road departments for producing asphalt mixes, in which the goal is to fit formulated gradation curves into the thresholds of gradation bands. With regards to the theoretical method, also named rational, it comprises a discrete selection of particle diameters in sieving plants, allowing to control precisely the percent distribution of the grains, without the need 
to consider gradation bands, by using Füller-Talbot equations. The controlled method means an adjustment performed in that research, in which was proceeded the individual fractioning of the granular particles predicted to by trial formulation, however, maintaining the same sieve sequence and the percent distribution originally adopted. They were characterized and used granular particles provided by gneissic crushed massive rock located in the metropolitan region of Joinville/SC and bituminous binder 50/70 $(0.1 \mathrm{~mm})$ penetration supplied by a refinery placed in Paulínia/SP. They were tested mechanical properties such as compacting ability with Compacting Shear Press, resistance to deleterious action of water in Duriez test at $18^{\circ} \mathrm{C}$ and to rutting, while functional properties as macrotexture and surface run-off time were evaluated by sand path height and drainability tests. The results obtained indicate the theoretical method is more efficient than the others studied, due to have presented the best mechanical and functional indicators in all evaluated parameters, while the method by trial proved to be the worst technically, and should be replaced by a more scientific and accurate methodology in Brazil.

Keywords: Aggregate gradations; Dense asphalt mixes; Formulation methods; Mechanical properties; Functional properties.

\section{INTRODUÇÃO}

O transporte no Brasil se dá em sua maioria pelo modal rodoviário, portanto, decisivo na economia do país. Grande parte das estradas brasileiras encontra-se danificada, e segundo MORILHA [1], isso ocorre devido a diversos fatores, podendo ser citados a má formulação das misturas asfálticas, o excesso de carga sobre o pavimento, a falta de manutenção e falha nos processos executivos.

De acordo com Barra [2], o projeto e execução dos pavimentos devem atender de forma satisfatória a trilogia conforto, segurança e economia. Para tal, é necessário o estudo constante das propriedades dos materiais, a fim de garantir bom desempenho mecânico e funcional, com necessidade mínima de reparos e manutenção em campo.

Os principais parâmetros que implicam diretamente na qualidade e vida útil das misturas asfálticas estão relacionados à composição da matriz granular e à natureza do ligante betuminoso. Logo, o conhecimento dos materiais envolvidos faz-se necessário para especificar adequadamente os insumos e técnicas de concepção a serem utilizados [3-6]. Contudo, no que diz respeito à formulação granulométrica, o maior desafio do projetista é escolher o método mais adequado dentre as considerações existentes ou propostas, de modo a obter dosagens que garantam melhores resultados nas aplicações práticas [7].

Os cenários produtivos e comerciais dos insumos destinados à pavimentação nacional ainda apresentam algumas dificuldades, sendo uma delas o beneficiamento dos granulares que geralmente não apresentam uma constância na forma, nem nos tamanhos das frações correspondentes a um determinado diâmetro, resultando assim, composições granulométricas heterogêneas em uma mesma fração comercial, logo, pouco estáveis, devido à deficiência quanto ao preenchimento gradual dos volumes de vazios formados pelas partículas de maiores dimensões. Não havendo uma padronização no beneficiamento dos granulares, as dosagens das misturas asfálticas ficam suscetíveis a resultados ruins em campo, uma vez que composições granulométricas com formulação inadequada podem causar forte instabilidade mecânica às misturas [8].

No Brasil, atualmente utiliza-se do conhecimento empírico e da subjetividade do projetista. As especificações técnicas nacionais, isto é, faixas granulométricas dos departamentos rodoviários oficiais brasileiros, não propõem nenhuma metodologia de critério técnico racional, servindo apenas como instrumento de verificação final da curva granulométrica escolhida [9].

Diversos autores [10- 19] mencionam a relação entre desempenho de misturas asfálticas com as características de sua distribuição granulométrica, a qual se mal concebida afeta prejudicialmente as propriedades funcionais e estruturais da estrutura do pavimento, provocando danos como a deformação permanente, fluência excessiva, exsudação, desagregação, textura superficial inadequada, e até mesmo a fadiga precoce.

A escolha de uma composição granulométrica bem formulada tem um impacto positivo no desempenho reológico, mecânico e funcional das misturas asfálticas e, consequentemente, propicia uma redução nos gastos com manutenção. Assim, é importante a escolha de métodos tecnicamente adequados para a formulação de curvas granulométricas, que permitam as camadas betuminosas resistirem aos esforços oriundos do tráfego, bem como propiciar condições funcionais adequadas como boa rugosidade superficial e drenabilidade, evitando defeitos precoces em sua estrutura e a ocorrência de fenômenos como efeito spray e hidroplanagem [11].

Dado o exposto, propõe-se nesta pesquisa a avaliação comparativa de misturas asfálticas densas compostas por curvas granulométricas formuladas a partir de três métodos distintos, a saber: tentativa, teórico 
(racional) e controlado. São tomados em conta parâmetros relativos às propriedades mecânicas como habilidade de compactação com a Prensa de Compactação por cisalhamento Giratório (PCG), resistência à ação deletéria da água no ensaio de Duriez a $18^{\circ} \mathrm{C}$, e resistência à deformação permanente e, funcionais, a partir da avaliação da macrotextura pela altura da mancha de areia e da drenabilidade, em que o objetivo principal é determinar qual dos métodos mencionados é capaz de proporcionar misturas asfálticas com o melhor desempenho, considerando as prerrogativas técnicas estabelecidas na metodologia francesa, escolhida nesta pesquisa devido possuir estreita e comprovada relação campo/laboratório [20], contribuindo desta forma para a melhoria científica do processo de formulação de misturas asfálticas no Brasil.

\section{MATERIAIS E MÉTODOS}

A campanha experimental desta pesquisa foi realizada no Laboratório de Desenvolvimento e Tecnologia em Pavimentação (LDTPav) do Campus de Joinville da Universidade Federal de Santa Catarina (UFSC) e no Laboratório de Técnicas em Pavimentação (LTP) da Escola Politécnica da Universidade de São Paulo (USP).

O material pétreo utilizado é oriundo de britagem de maciço rochoso gnáissico e foi obtido a partir de jazida situada na região metropolitana de Joinville/SC, enquanto o ligante betuminoso de penetração 50/70 $(0,1 \mathrm{~mm})$ é proveniente de refinaria localizada na cidade de Paulínia/SP (Tabela 1).

Tabela 1: Caracterização do material pétreo e do ligante betuminoso [7].

\begin{tabular}{|c|c|c|c|}
\hline ENSAIO & $\begin{array}{l}\text { RESULTADO EM } \\
\text { LABORATÓRIO }\end{array}$ & $\begin{array}{c}\text { LIMITE } \\
\text { NORMATIVO }\end{array}$ & NORMA \\
\hline \multicolumn{4}{|c|}{ MATERIAL PÉTREO } \\
\hline Desgaste por Abrasão Los Angeles & $17,5 \%$ & $\leq 50 \%$ & $\begin{array}{c}\text { DNER-ME 35/98 [21] e } \\
\text { DNER-EM 37/97 [22] }\end{array}$ \\
\hline Durabilidade ao Sulfato de Sódio & $5,3 \%$ & $\leq 12 \%$ & $\begin{array}{c}\text { DNER-ME 89/94 [23] e } \\
\text { DNER-EM } 37 / 97 \text { [22] }\end{array}$ \\
\hline Índice de Forma (Lamelaridade) & 0,6 & $\geq 0,5$ & ABNT NBR 7809/2006 [24] \\
\hline Adesividade ao Agregado Graúdo & Má & - & DNER-ME 78/94 [25] \\
\hline Equivalente de Areia & $78 \%$ & - & DNER-ME 54/97 [26] \\
\hline Teor de Material Pulverulento & $0,4 \%$ & $\leq 1,0 \%$ & $\begin{array}{c}\text { DNER-ME 266/97 [27] e } \\
\text { DNER-EM 37/97 [22] }\end{array}$ \\
\hline \multicolumn{4}{|c|}{ Ligante Betuminoso 50/70 } \\
\hline Penetração $(0,1 \mathrm{~mm})$ & 52 & $50-70$ & DNIT-ME 155/2010 [28] \\
\hline $\begin{array}{c}\text { Ponto de Amolecimento } \\
\text { Anel e Bola }\left({ }^{\circ} \mathrm{C}\right)\end{array}$ & 49 & $>46$ & DNIT-ME 131/2010 [29] \\
\hline $\begin{array}{c}\text { Índice de Pfeiffer e } \\
\text { Van Doormaal }\end{array}$ & $-1,5$ & $-1,5 \mathrm{a}+0,7$ & $\begin{array}{l}\text { Resolução }{ }^{\circ} 19 \\
(\mathrm{ANP}, 2005) \text { [30] }\end{array}$ \\
\hline Viscosidade Saybolt-Furol & $\begin{array}{c}137^{\circ} \mathrm{C} \mathrm{a} 142^{\circ} \mathrm{C}(\mathrm{com}- \\
\text { pactação); } 148^{\circ} \mathrm{C} \mathrm{a} \\
153^{\circ} \mathrm{C} \\
\text { (usinagem) } \\
\end{array}$ & - & ABNT NBR 14950/2003 [31] \\
\hline Massa Específica Real $\left(\mathrm{g} / \mathrm{cm}^{3}\right)$ & 1,007 & - & ABNT NBR 6296/2012 [32] \\
\hline
\end{tabular}

Importante destacar a má adesividade do granular gnáissico ao ligante betuminoso, em razão de sua composição mineralógica majoritariamente $(60 \%)$ quartzosa $\left(\mathrm{Si}^{-4} \mathrm{O}_{2}{ }^{-2}\right)$ [33] repelir as moléculas carbônicas $\left(\mathrm{C}^{-4}\right)$ que formam mais de $80 \%$ da formulação do ligante betuminoso [34], pois ambos os elementos citados são de característica eletronegativa. Entretanto, não foi utilizado nesta pesquisa nenhum melhorador de adesividade na dosagem das misturas asfálticas, com o intuito de preservar as características originais dos insumos, para que não tivessem qualquer influência nos resultados da campanha experimental e, portanto, permitindo a verificação do real efeito das composições granulométricas nas propriedades mecânicas e funcionais testadas.

No que diz respeito às curvas granulométricas, tem-se que três composições foram concebidas, a saber: curva teórica (CT), curva prática (CP) e curva controlada (CC).

Para a composição da CT utilizou-se a curva proposta por Barra [2] (Tabela 2), com base no método teórico, também denominado racional, a partir das equações (1) e (2) de Füller-Talbot, fixando-se os parâmetros característicos da curva granulométrica que se deseja formular (diâmetro máximo, percentual passante de 
partículas na malha de menor abertura da série, e expoente de graduação), levando em conta a produção de frações individuais correspondentes a cada malha da série de peneiras escolhida pelo projetista, sem a necessidade de utilização de faixa granulométrica.

$$
\begin{gathered}
\% \mathrm{p}=\mathrm{a} \cdot\left(\frac{\mathrm{d}}{\mathrm{D}}\right) \\
\mathrm{n}=\frac{\log \left(\% \mathrm{p}_{0,075 \mathrm{~mm}}\right)-\log (100)}{\log \left(\frac{0,075}{\mathrm{D}}\right)}
\end{gathered}
$$

Onde '\%p' é a percentagem em peso passante; 'a'é uma constante, tomada igual a 100; 'd' é a abertura de uma dada peneira $(\mathrm{mm})$; 'D’ é o diâmetro máximo, correspondente à abertura da peneira em que passa $100 \%$ das frações (mm); 'n' é o expoente indicador de graduação da curva (se mais aberta ou mais densa, por exemplo); e ‘ $\% \mathrm{p}_{0,075 \mathrm{~mm}}$ ' é o percentual passante na menor abertura de peneira da série $(0,075 \mathrm{~mm})$.

Tabela 2: Composição das frações granulares da curva teórica (CT) [2].

\begin{tabular}{ccc} 
Abertura de Peneiras (mm) & Percentagem Passante (\%) & Percentagem Retida (\%) \\
\hline 19,1 & 100,0 & - \\
\hline 12,7 & 81,3 & 18,7 \\
\hline 9,50 & 70,1 & 11,1 \\
\hline 4,76 & 49,4 & 20,8 \\
\hline 2,20 & 33,4 & 16,6 \\
\hline 1,20 & 24,5 & 8,8 \\
\hline 0,60 & 17,2 & 7,3 \\
\hline 0,30 & 12,1 & 5,1 \\
\hline 0,15 & 8,5 & 3,6 \\
\hline 0,075 & 6,0 & 2,5 \\
\hline- & - & 6,0 \\
\hline
\end{tabular}

Observando-se a Tabela 2, tem-se que o diâmetro máximo corresponde a 19,1mm, o percentual passante na peneira de menor abertura da série $(0,075 \mathrm{~mm})$ é de $6,0 \%$, e o expoente 'n' obtido é 0,51 , o que significa uma composição granulométrica densa, de acordo com o Departamento Nacional de Infraestrutura de Transportes (DNIT) [35]. A escolha do percentual de 6,0\% mencionado foi realizada com base na pesquisa de MOMM [11], em que após extenso estudo bibliográfico verificou que as curvas granulométricas formuladas por métodos teóricos que apresentaram os melhores resultados mecânicos e funcionais tinham percentual passante na peneira $0,075 \mathrm{~mm}$ entre $5,0 \%$ e $7,0 \%$.

A curva granulométrica prática $(\mathrm{CP})$ foi formulada pelo método por tentativa, a partir do enquadramento em faixas limítrofes das frações granulométricas comerciais heterogêneas, isto é, sem a definição do peneiramento discretizado de cada diâmetro de partícula, normalmente utilizadas pelas empresas de pavimentação no Brasil. Nesta pesquisa, particularmente, foi utilizada a graduação da Faixa C do Departamento de Estradas de Rodagem do Estado do Paraná (DER/PR) [36] (Tabela 3), utilizada em algumas obras da região norte do Estado de Santa Catarina, com destaque para a região metropolitana de Joinville/SC, bem como no próprio Estado do Paraná em toda a sua extensão. 
Tabela 3: Composição das frações granulares da curva prática (CP) $[7,36]$.

\begin{tabular}{|c|c|c|c|}
\hline $\begin{array}{l}\text { ABERTURA } \\
\text { DE PENEI- } \\
\text { RAS (MM) }\end{array}$ & $\begin{array}{l}\text { PERCENTAGEM } \\
\text { PASSANTE (\%) }\end{array}$ & $\begin{array}{c}\text { FRAÇÕES } \\
\text { COMERCIAIS }\end{array}$ & $\begin{array}{c}\text { PERCENTAGEM DAS FRAÇÕES } \\
\text { COMERCIAIS ENQUADRADAS POR } \\
\text { TENTATIVA NA FAIXA C } \\
\text { DO DER/PR (\%) }\end{array}$ \\
\hline 25,4 & 100 & \multirow{3}{*}{ Brita 3/4" } & \multirow{3}{*}{30} \\
\hline 12,7 & 100 & & \\
\hline 9,5 & 74,2 & & \\
\hline 4,76 & 49,3 & \multirow{2}{*}{ Pedrisco } & \multirow{2}{*}{21} \\
\hline 2,2 & 28,1 & & \\
\hline 0,42 & 12,5 & \multirow{2}{*}{ Pó de Pedra } & \multirow{2}{*}{49} \\
\hline 0,075 & 6,6 & & \\
\hline
\end{tabular}

Quanto à curva granulométrica controlada (CC), esta foi formulada a partir de um ajuste denominado método controlado nesta pesquisa, correspondente à correção percentual das descontinuidades apresentadas na trajetória da $\mathrm{CP}$, ou seja, fazendo-se um controle das frações retidas peneira por peneira referente aos percentuais passantes obtidos por tentativa na Tabela 3 , a fim de torná-la contínua e, consequentemente, com melhor distribuição das frações em sua trajetória (Tabela 4).

Tabela 4: Composição das frações granulares da curva prática com controle de frações (CC) [7].

\begin{tabular}{ccc}
\hline $\begin{array}{c}\text { ABERTURA DE } \\
\text { PENEIRAS (MM) }\end{array}$ & $\begin{array}{c}\text { PERCENTAGEM } \\
\text { PASSANTE (\%) }\end{array}$ & $\begin{array}{c}\text { PERCENTAGEM } \\
\text { RETIDA (\%) }\end{array}$ \\
\hline 25,4 & 100 & - \\
\hline 12,7 & 100 & - \\
\hline 9,5 & 74,2 & 25,8 \\
\hline 4,76 & 49,3 & 24,9 \\
\hline 2,2 & 28,1 & 21,2 \\
\hline 0,42 & 12,5 & 15,6 \\
\hline 0,075 & 6,6 & 5,9 \\
\hline- & - & 6,6 \\
\hline
\end{tabular}

De acordo com o critério de Duriez previsto na equação (3) [20], o qual leva em conta a distribuição percentual granulométrica das formulações, a superfície específica das misturas asfálticas CT, CP e CC são $11,15 \mathrm{~m}^{2} / \mathrm{kg}, 15,55 \mathrm{~m}^{2} / \mathrm{kg}$ e $12,09 \mathrm{~m}^{2} / \mathrm{kg}$, respectivamente.

$$
100 \Sigma=0,25 \mathrm{G}+2,3 \mathrm{~S}+12 \mathrm{~s}+150 \mathrm{f}
$$

Onde ' $\Sigma$ ' é a superfície específica $\left(\mathrm{m}^{2} / \mathrm{kg}\right)$ da curva granulométrica, ' $\mathrm{G}$ ' a percentagem de granulares na curva superior a $6,3 \mathrm{~mm}$, ' $\mathrm{S}$ ' a percentagem de granulares na curva entre $6,3 \mathrm{~mm}$ e $0,250 \mathrm{~mm}$, ' $\mathrm{s}$ ' a percentagem de granulares na curva entre $0,250 \mathrm{~mm}$ e $0,063 \mathrm{~mm}$ e, ' $\mathrm{f}$ ' a percentagem de agregados na curva abaixo de $0,063 \mathrm{~mm}$.

As curvas granulométricas formuladas também foram comparadas aos pontos de controle da proporção das frações granulares estabelecidos pela metodologia francesa [20], no que diz respeito às misturas densas do tipo Béton Bitumineux Semi-Grenus (BBSG), definidas em maiores detalhes nos parágrafos seguintes, a saber: $\mathrm{D}_{\text {máx }}(90 \%-100 \%) ; 6,3 \mathrm{~mm}(50 \%-65 \%) ; 2,0 \mathrm{~mm}(28 \%$ - 38\%); 0,25 (10\% - 25\%) e 0,063mm $(5 \%$ $8 \%$ ).

A Figura 1 ilustra a disposição das curvas granulométricas concebidas para esta pesquisa. 


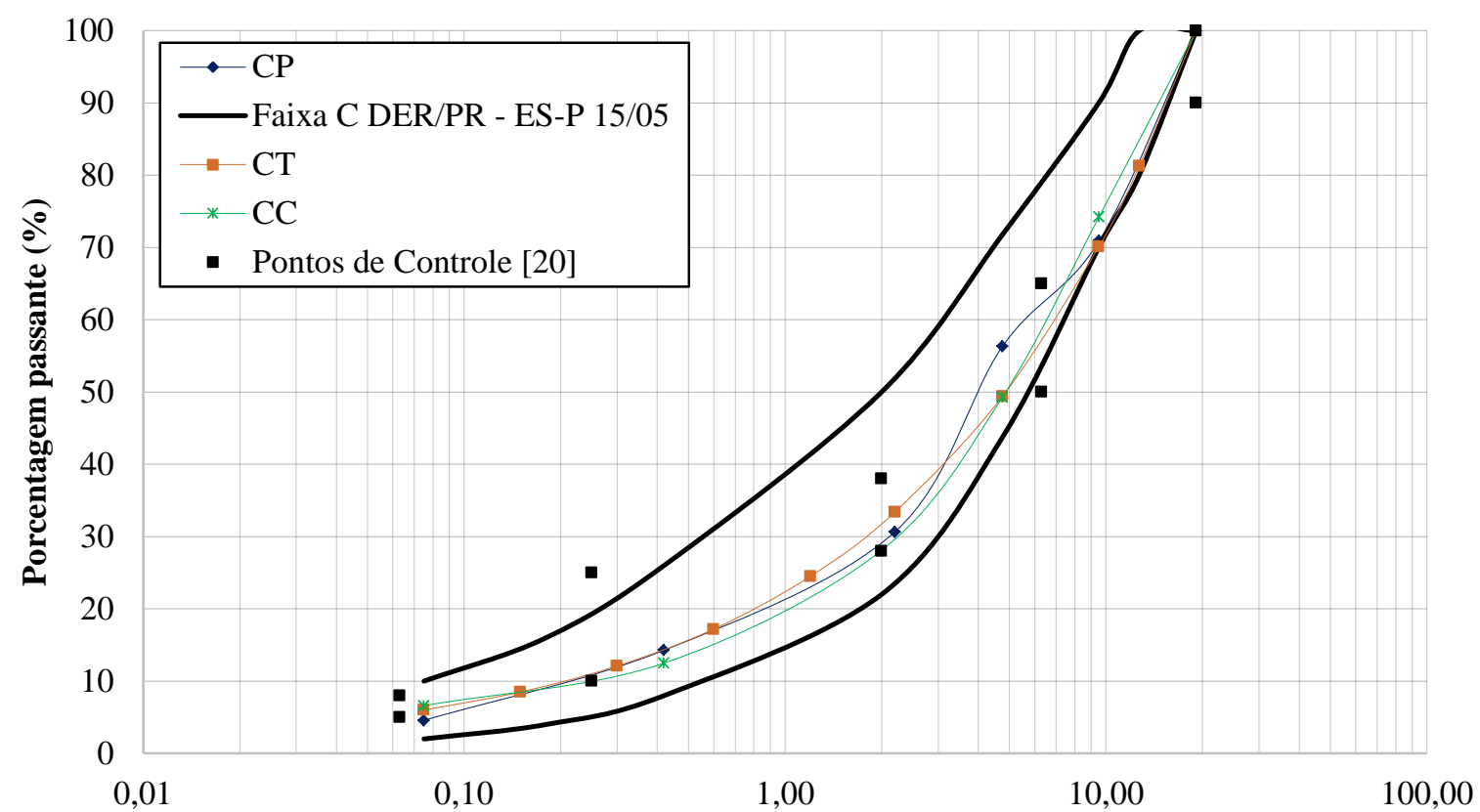

Abertura das peneiras (mm)

Figura 1: Curvas granulométricas enquadradas na faixa C DER/PR [7].

É possível observar na Figura 1 que todas as curvas granulométricas formuladas enquadram-se nos intervalos da faixa $\mathrm{C}$ proposta pelo DER/PR. Ainda, cabe ressaltar que a CT possui um caráter racional, ou seja, utiliza a equação de Füller-Talbot, a qual permite - a partir da fixação de ' $\mathrm{D}$ ', ‘\% $\mathrm{p}_{0,075 \mathrm{~mm}}$ ' e 'n', além da adoção de uma série de peneiras com malhas sequenciais à razão próxima da metade da abertura anterior nas malhas finas - desenvolver continuamente e de forma bem definida a trajetória da curva granulométrica, acarretando a obtenção de uma composição que possibilita o preenchimento gradual dos vazios formados pelas partículas de maior diâmetro que compreendem a curva. Por estas razões, não necessita enquadrar-se necessariamente nos limites especificados por faixas, até mesmo por não ser formulada sob esta perspectiva.

Em contrapartida, verifica-se que a distribuição das aberturas de malhas da CP e CC não possibilita um preenchimento gradual dos vazios, pois só há uma peneira entre os diâmetros de $2,2 \mathrm{~mm}$ e o de $0,075 \mathrm{~mm}$, enquanto na curva CT há quatro peneiras neste intervalo. Importante salientar que esta deficiência também pode ser verificada nas faixas A, B e C do Departamento Nacional de Infraestrutura de Transportes [37], em que apenas duas peneiras perfazem o intervalo acima descrito, logo, demonstrando que esta é uma característica comum das distribuições granulométricas adotadas no Brasil.

Além disso, é perceptível na Figura 1 uma descontinuidade acentuada na trajetória da curva CP entre os diâmetros $9,5 \mathrm{~mm}$ e $2,2 \mathrm{~mm}$, indicando a dificuldade de controle do projetista sobre a composição simultânea de diversas frações comerciais heterogêneas nos limites das faixas normativas, fator corrigido com o ajuste dos percentuais na curva $\mathrm{CC}$, a partir do método controlado.

Importante destacar que todas as curvas granulométricas concebidas para esta pesquisa são enquadradas na categoria de mistura do tipo Béton Bitumineux Semi Grenus (BBSG) da metodologia francesa de formulação de misturas asfálticas [20], ou seja, com característica densa, aplicável tanto em camada de rolamento como de ligação (Figura 2), com espessuras esbeltas que podem variar no campo de $5,0 \mathrm{~cm}$ a $9,0 \mathrm{~cm}$. Para se ter um parâmetro de comparação em relação às espessuras, as camadas asfálticas estruturais nos pavimentos franceses, que suportam os esforços de tração gerados pelo tráfego, podem chegar a $16,0 \mathrm{~cm}$, como as misturas de módulo elevado (Enrobé à Module Élevé - EME) ou Grave-Bitume (GB), em que ambas podem ser utilizadas tanto em camadas de base quanto de sub-base dos pavimentos. Desta forma, as misturas BBSG podem ser aplicadas em soluções de pavimentação no Brasil, tanto em serviços de construção quanto de restauração, na espessura de 5,0cm quando utilizada como camada superficial de rolamento, e na condição de camada de ligação, de $6,0 \mathrm{~cm}$ a $7,0 \mathrm{~cm}$ para tráfegos leves a médios, e de $8,0 \mathrm{~cm}$ a $9,0 \mathrm{~cm}$ para tráfegos pesados. 


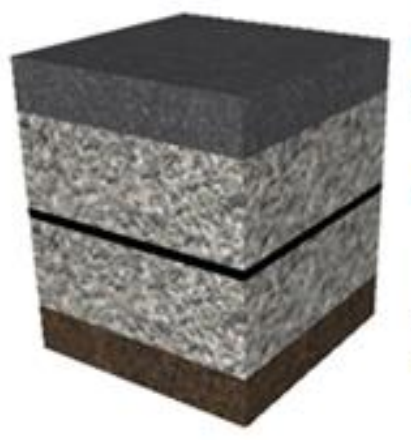

\section{Camada de rolamento/ligação betuminosa}

\section{Camadas estruturais betuminosas}

\section{Plataforma de fundação}

Figura 2: Estrutura típica de um pavimento francês destinado a trafego intenso de cargas e com volume elevado de solicitações [38].

Desta forma, as suas principais características são propiciar em campo condições adequadas de conforto, a partir da resistência ao afundamento na trilha de roda; segurança, com boa rugosidade e rápido escoamento superficial da água, garantindo aderência pneu-pavimento eficiente, além da não ocorrência do fenômeno de hidroplanagem e do efeito spray, e; economia, protegendo as camadas estruturais da ação direta das intempéries, como a precipitação pluviométrica, radiação solar e óleos solventes, propiciando ao pavimento maior tempo de vida útil e menor custo com manutenção [7].

Portanto, não possui função estrutural, e por esta razão não é considerada no dimensionamento de estruturas de pavimento pela metodologia francesa [38]. Logo, não necessitam ser avaliadas a partir dos ensaios fundamentais de módulo complexo e fadiga, apenas até o nível 2 de deformação permanente, conforme ilustra a sequência da Figura 3. Assim, todos os parâmetros de avaliação foram considerados com base neste tipo de mistura asfáltica (BBSG) para os ensaios executados e resultados obtidos.

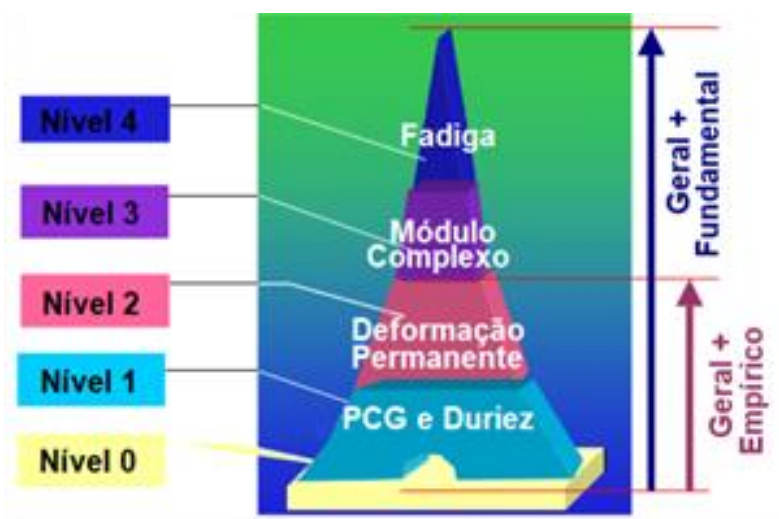

Figura 3: Níveis de formulação das misturas asfálticas pela metodologia francesa [20].

É importante esclarecer que os níveis 0 (correspondente à caracterização dos materiais), 1 e 2, considerados empíricos, apenas são colocados neste âmbito de classificação por avaliarem fenômenos considerados caóticos, como: o desenvolvimento contínuo do afundamento na trilha de roda, a acomodação da estrutura interna da mistura asfáltica durante o procedimento de compactação por cisalhamento e, a evolução da degradação na interface granular/ligante provocada pela tensão superficial da água. Portanto, situações complexas e dinâmicas de difícil modelagem físico-matemática acurada das variáveis envolvidas [39, 40, 41], e por isso devem ser verificadas em cada caso, diretamente sobre as amostras formuladas para teste.

A densidade real das misturas foi determinada no ensaio de Massa Volumétrica Real (MVR) [42] (Figura 4; Tabela 5), com utilização de bomba de vácuo com pressão de $0,05 \mathrm{MPa}$, considerando os seguintes teores de ligante para teste: $4,22 \%, 4,54 \%, 4,86 \%, 5,18 \%$ e 5,50\% para a mistura CT, e; 4,00\%, 4,50\%, 5,00\%, $5,50 \%$ e $6,00 \%$ para as misturas $\mathrm{CP}$ e CC [7]. Os teores de ligante para a mistura CT foram escolhidos com base nos estudos de Barra [2], enquanto para as curvas CP e CC foram selecionados percentuais usualmente trabalhados nos estudos de dosagem em laboratório com misturas asfálticas densas formuladas a partir de faixas granulométricas, mais especificamente a faixa $\mathrm{C}[1,8,9]$. 


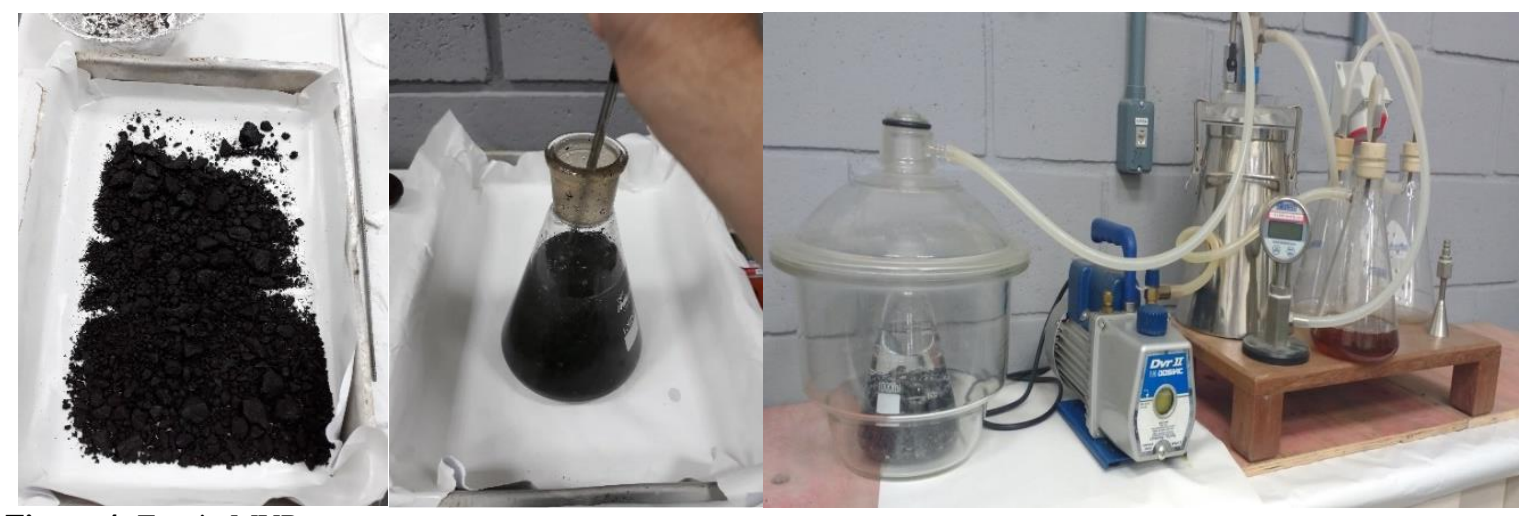

Figura 4: Ensaio MVR.

Tabela 5: MVR das misturas asfálticas.

\begin{tabular}{ccc} 
Mistura Asfáltica & Teor de Ligante (\%) & MVR ( $\left./ \mathbf{c m}^{\mathbf{3}}\right)$ \\
\hline & 4,22 & 2,634 \\
& 4,54 & 2,629 \\
CT & 4,86 & 2,626 \\
& 5,18 & 2,612 \\
& 5,50 & 2,603 \\
\hline \multirow{2}{*}{ CPA } & 4,00 & 2,669 \\
& 4,50 & 2,638 \\
& 5,00 & 2,617 \\
& 5,50 & 2,600 \\
& 6,00 & 2,569 \\
\hline \multirow{2}{*}{ CP } & 4,00 & 2,648 \\
& 4,50 & 2,635 \\
& 5,00 & 2,609 \\
& 5,50 & 2,601 \\
& 6,00 & 2,572 \\
\hline
\end{tabular}

A partir dos mesmos teores de ligante utilizados no ensaio de MVR, foi dada continuidade à pesquisa no que diz respeito à avaliação do comportamento mecânico das misturas asfálticas, compreendendo parâmetros como habilidade de compactação com a Prensa de Compactação por cisalhamento Giratório (PCG) [43], resistência à ação deletéria da água no ensaio de Duriez a $18^{\circ} \mathrm{C}$ [44], e resistência à deformação permanente [45], nesta ordem. Cabe ressaltar que estes ensaios possuem caráter eliminatório na metodologia francesa, isto é, caso uma dosagem não seja aprovada em algum destes procedimentos no transcurso da sequência mencionada, é rejeitada imediatamente, não podendo seguir adiante com a sua avaliação.

No ensaio da PCG foram testados 3 corpos de prova para cada teor de ligante, a partir de uma compactação lenta e isotérmica sob baixa compressão estática, executada por um movimento giratório cisalhante de uma de suas faces em torno do eixo de simetria do corpo de prova (Figura 5). 


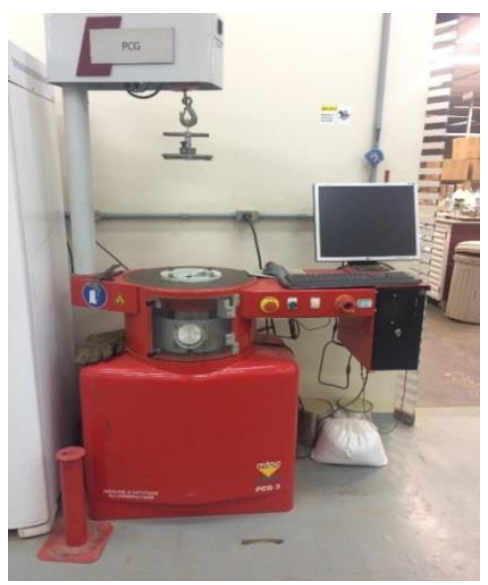

(a)

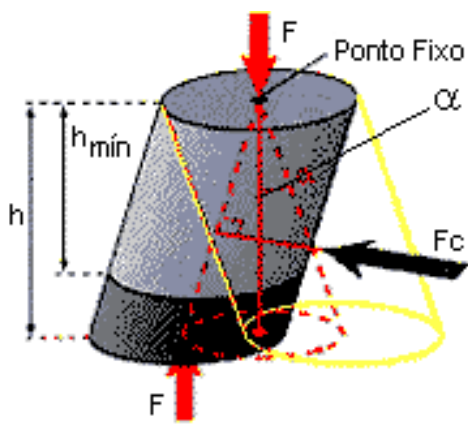

(b)

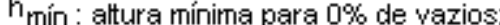

$h$ : altura aparente para $N$ giros;

$F$ : força axial;

$\mathrm{Fc}$ : força de cisalhamento;

$\alpha$ : ângulo de inclinaçẫo.

Figura 5: (a) Prensa de Compactação Giratória (PCG-3) e, (b) seu princípio de funcionamento [20].

A altura mínima $\left(\mathrm{h}_{\text {mín }}\right)$ dos corpos de prova é estipulada em 150,0mm, para moldes com diâmetro interno de $150,0 \mathrm{~mm} \pm 0,1 \mathrm{~mm}$. Nestes casos, as massas dos corpos de prova são calculadas com base no volume final da amostra e na massa volumétrica real (MVR) da mistura, conforme demonstra a equação (4).

$$
M=2,651 \cdot M V R ; \phi=150,0 \mathrm{~mm}
$$

Onde ' $\mathrm{M}$ ' é a massa do corpo de prova ( $\mathrm{g})$, 'MVR' é a massa volumétrica real da mistura asfáltica determinada no ensaio a vácuo $\left(\mathrm{g} / \mathrm{cm}^{3}\right)$, e ' $\varphi$ ' é o diâmetro considerado do molde do corpo de prova para cálculo do volume da amostra de $2,651 \mathrm{~cm}^{3}$.

A força aplicada no momento do ensaio deve ser estar entre $10 \mathrm{kN}$ e $12 \mathrm{kN}$, o que resulta em uma tensão vertical em torno de $0,6 \mathrm{MPa}$. Os valores médios da força aplicada durante um ensaio normal, com exceção de um período transitório de início inferior a 30 segundos, não devem ter uma variação maior que $\pm 250 \mathrm{~N}$ em relação à faixa de limites determinada, enquanto que no caso de uma verificação a cada giro do eixo, este valor médio não pode variar além de $\pm 1200 \mathrm{~N}$ ao longo do ensaio.

O ângulo de rotação $(\alpha)$ do molde em função do eixo de aplicação da força durante o ensaio é calibrado com base em uma amostragem de 27 corpos de prova com composições granulométricas pré-determinadas normativamente [43], a partir de um binário que abrange vários intervalos de percentagens de vazios e número de giros da máquina, e seus respectivos desvios-padrão. Estes ângulos $(\alpha)$ variam conforme o tipo de PCG disponível. Para a PCG-3 utilizada nesta pesquisa, estas inclinações são de $1^{\circ}$ e de $0,82^{\circ}$ nas partes externa e interna dos corpos de prova, respectivamente, em que a formulação BBSG para que seja considerada conforme deve possuir teor de vazios compreendido entre $4 \%$ a $9 \%$ depois de submetida a 80 giros do equipamento, determinados pela equação 5 .

$$
\% v=100 .\left(\frac{h_{(n g)}-h_{m i n}}{h_{(n g)}}\right)
$$

Onde '\%v' é o percentual de vazios a um dado número de giros; ' $\mathrm{h}_{(\mathrm{ng})}$ ' altura do corpo de prova a um dado número de giros $(\mathrm{mm})$; ' $\mathrm{h}_{\text {mín }}$ ' é a altura mínima especificada no ensaio para finalização do ensaio, de acordo com o tipo de PCG utilizada, neste caso $150,0 \mathrm{~mm}$.

Para o ensaio de Duriez a $18^{\circ} \mathrm{C}$ foram moldados 12 corpos de prova por teor de ligante, à compressão por duplo pistão com carga constante de 6,0t durante 5 minutos, subdivididos em 2 grupos de 6 unidades, com massa total de $1,0 \mathrm{~kg}$ cada. Deste total, metade foi submetido a condicionamento submerso em água com prévia saturação dos vazios a vácuo com pressão de $0,05 \mathrm{MPa}$, e outra metade conservada em câmara climatizadora com controle da umidade do ar em $50 \% \pm 10 \%$, em ambos os casos a temperatura ambiente foi mantida a $18^{\circ} \mathrm{C}$ por 7 dias. Após este período, as amostras foram submetidas à aplicação de esforço de compressão simples fazendo-se a relação de resistência entre as unidades condicionadas na água (r) e condicionadas a 
seco (R), em que para misturas do tipo BBSG este valor não pode ser inferior a $30 \%$ de perda ou 0,70 . A Figura 6 a sequência operacional do ensaio.

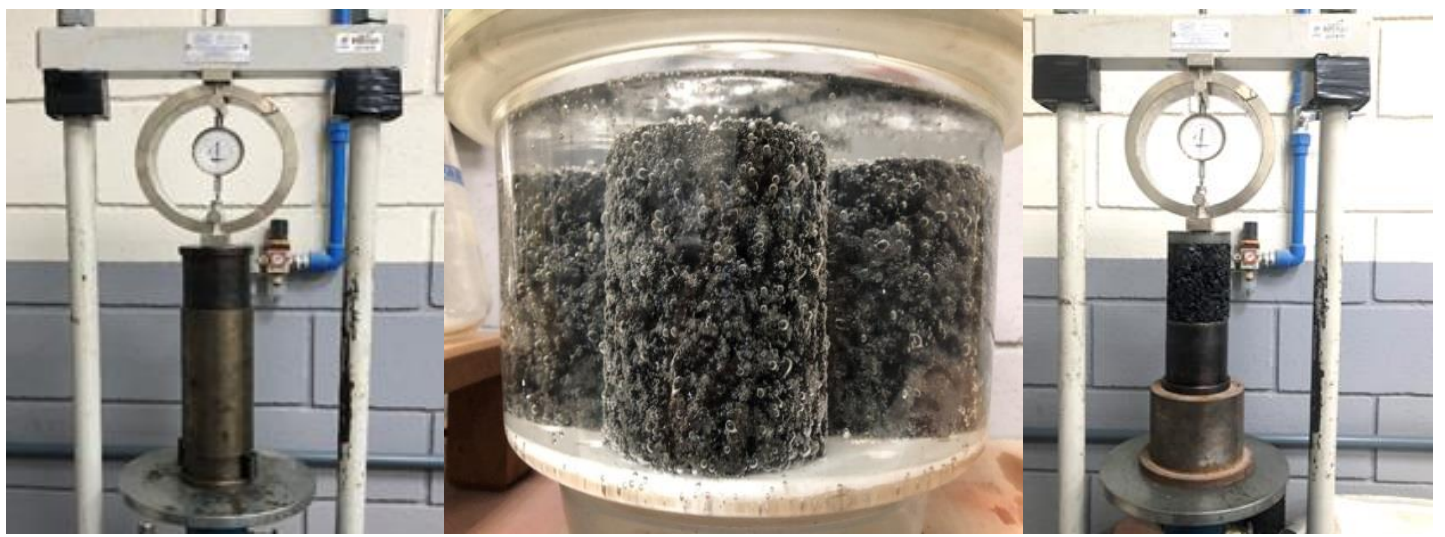

Figura 6: Ensaio de Duriez a $18^{\circ} \mathrm{C}$.

Para o ensaio de deformação permanente foram moldadas 2 placas para cada teor de ligante, em mesa compactadora pneumática com 180mm (largura), 500mm (comprimento) e 100mm (espessura), (Figura 7a). Após 15 dias de repouso cada par foi acoplado por vez à plataforma da máquina do ensaio, percorrendo o eixo solicitante a superfície das placas em ciclos com frequência constante de $1 \mathrm{~Hz}$, à temperatura controlada de $60^{\circ} \mathrm{C}$ no interior da câmara climatizadora, sempre na mesma trilha de roda (Figura 7b).

Os esforços são transmitidos às placas por pneumáticos de borracha com textura lisa, para que não haja indução de deformações localizadas pelas esculturas dos materiais rodantes, aplicando carga de $5 \mathrm{kN}$ e pressão de inflação da ordem de $0,6 \mathrm{MPa}$, controladas por um sistema de comando eletromecânico. A cada duas passagens (ida e volta) do eixo resultam um ciclo.

Antes do início dos ciclos é necessário que a temperatura no interior da câmara térmica atinja a temperatura mencionada, consumindo para isto um tempo de, no mínimo, 4 horas de climatização inicial. Em seguida, são feitas medições em 15 pontos distintos das placas com 100, 300, 1000, 3000, 10000 e 30000 ciclos, obtendo-se a partir da equação 6 , para cada um destes ciclos, a média dos afundamentos gerados pela ação do carregamento, sempre em relação às medidas iniciais tomadas ainda com as placas em temperatura ambiente antes da aplicação dos primeiros ciclos (Figura 7c).

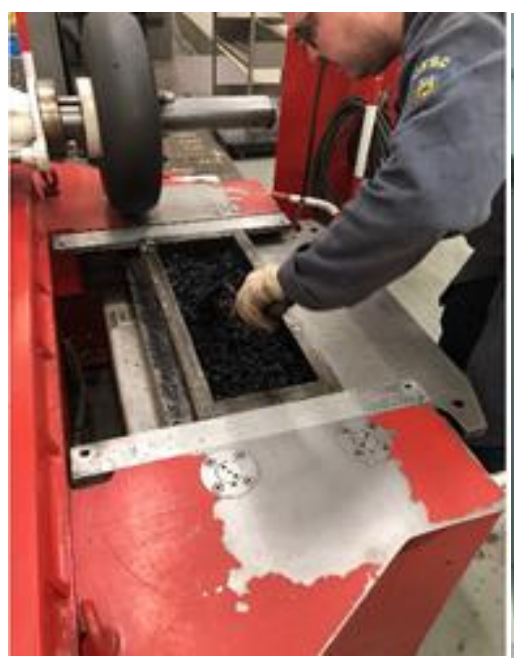

(a)

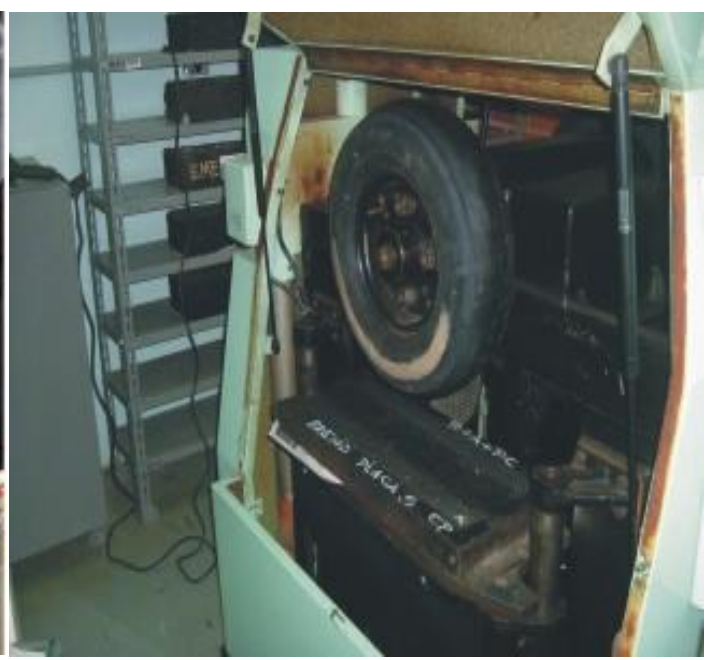

(b) 


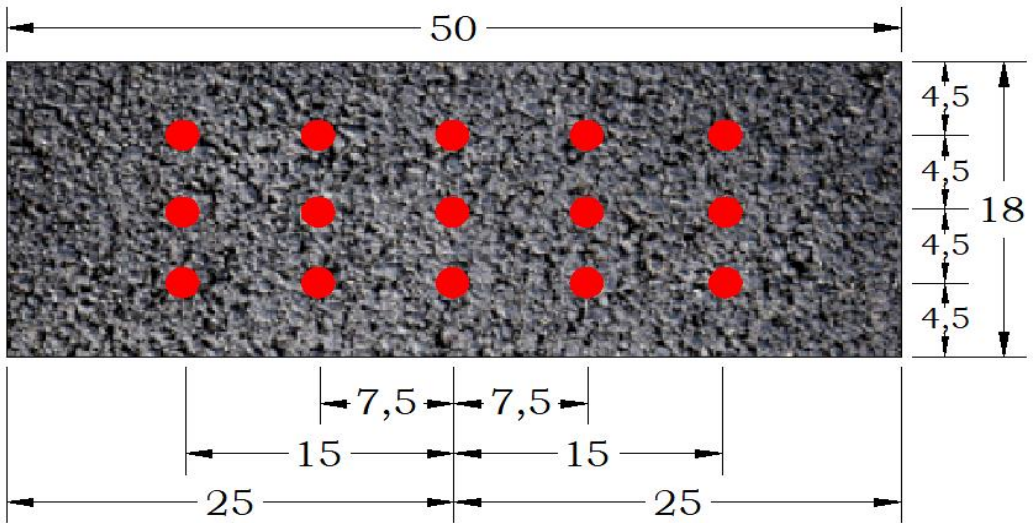

(c)

Figura 7: Procedimentos de (a) compactação de placas, (b) execução do ensaio de deformação permanente e, (c) medição dos afundamentos na trilha de roda.

$$
Y=A .\left(\frac{N}{1000}\right)^{b}
$$

Onde ' $\mathrm{Y}$ ' é o afundamento na trilha de roda; 'A' e ' $b$ ' são os coeficientes linear e angular, nesta ordem, estabelecidos estatisticamente e, ' $\mathrm{N}$ ' é o número de ciclos percorridos pelo eixo em cada etapa.

Para misturas do tipo BBSG há uma divisão de três classes a serem consideradas na interpretação dos resultados quanto ao percentual admissível do afundamento na trilha de roda após 30000 ciclos, a saber: Classe $3 \leq 5,0 \%$, Classe 2 entre 5,1\% e 7,5\%; Classe 1 entre 7,51\% e 10,0\% [20]. Quanto às classes mencionadas, tem-se que estão relacionadas às seguintes condições de aplicação no campo [46]:

- Classe 1: destinadas à aplicação em tráfegos de regiões com temperatura ambiente em torno de $15^{\circ} \mathrm{C}$;

- Classe 2: aplicadas a tráfegos em condições climáticas que envolvem elevados gradientes térmicos ao longo do ano, como por exemplo, temperatura ambiente de $5^{\circ} \mathrm{C}$ durante o inverno e de $30^{\circ} \mathrm{C}$ no verão;

- Classe 3: aplicadas a condições de tráfego particulares (tráfego canalizado, elevada solicitação, zonas de intersecção, rotatórias, por exemplo), bem como climas com temperaturas constantemente elevadas.

Logo, para aplicação no Brasil dos limites percentuais descritos anteriormente, as classes que mais se enquadram à realidade climática do país são a 2 e a 3 , dependendo da região considerada, sendo ainda a classe 3 a mais indicada entre todas, pois requer maior rigor em sua avaliação, logo é a mais nobre, seguida pela classe 2 , e finalmente, classe 1 .

Os ensaios de mancha de areia [47] e drenabilidade [48] foram executados, a fim de determinar indicadores funcionais de rugosidade e tempo de escoamento da água, respectivamente, considerando em ambos os casos a superfície da mistura asfáltica que estará em contato direto com o pneumático dos veículos em campo.

O ensaio de mancha de areia consiste em um método volumétrico e visa preencher os canais de curtose da textura superficial do pavimento, espalhando a areia padronizada (passante na peneira $\mathrm{n}^{\circ} 60$ e retido na peneira $\mathrm{n}^{\circ} 80$ ), formando um círculo com o auxílio do soquete com base emborrachada (Figura 8). 

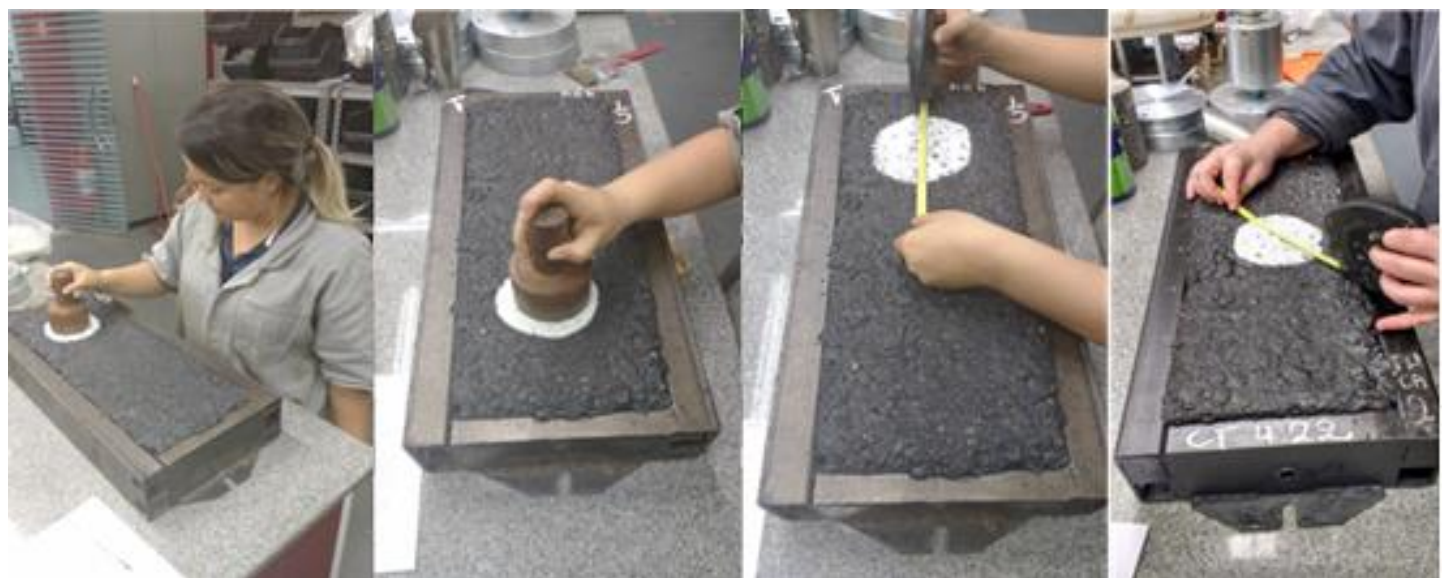

Figura 8: Ensaio de mancha de areia.

Cabe esclarecer que o volume padronizado de material (areia com morfologia esférica) de $25000 \mathrm{~mm}^{3}$ foi adaptado nesta pesquisa para a metade, ou seja, $12500 \mathrm{~mm}^{3}$, em razão das dimensões da placa de deformação permanente não comportarem o volume original de material a ser espalhado sobre a sua superfície, impedindo a correta execução do ensaio. Isto, porém, não acarreta em nenhum prejuízo dos resultados obtidos, pois são proporcionais às dimensões das placas testadas.

São realizadas medidas diametrais em quatro direções da circunferência formada, sendo adotado o valor médio, permitindo calcular a altura da macrotextura do pavimento pela equação 7 .

$$
\mathrm{HS}=\frac{4 \mathrm{~V}}{\pi \mathrm{D}_{\mathrm{m}}^{2}}
$$

Onde 'HS' é a altura média da macrotextura do pavimento $(\mathrm{mm})$; ' $\mathrm{V}$ ' é o volume de areia a ser espalhado $\left(\mathrm{mm}^{3}\right)$; ' $\mathrm{D}_{\mathrm{m}}$ ' é o diâmetro médio formado pelo espalhamento do material (mm).

A classificação proposta por Pasquet [49] referente aos limites de aplicação do revestimento em função da macrotextura foi utilizada nesta pesquisa como parâmetro (Tabela 6).

Tabela 6: Classes de textura superficial em função da altura de mancha de areia [49].

\begin{tabular}{|c|c|c|}
\hline $\begin{array}{c}\text { TEXTURA } \\
\text { SUPERFICIAL }\end{array}$ & $\begin{array}{l}\text { LIMITES DA ALTURA DA MAN- } \\
\text { CHA DE AREIA - HS (mm) }\end{array}$ & APLICAÇÃO DO REVESTIMENTO \\
\hline Muito fina & $\mathrm{HS}<0,20$ & Não deve ser utilizado \\
\hline Fina & $0,20 \leq \mathrm{HS} \leq 0,40$ & $\begin{array}{l}\text { Reservado para zonas urbanas } \\
\mathrm{V}<80 \mathrm{~km} / \mathrm{h}\end{array}$ \\
\hline Média & $0,40 \leq \mathrm{HS} \leq 0,80$ & $\begin{array}{l}\text { Indicado para vias com } \\
80 \mathrm{~km} / \mathrm{h}<\mathrm{V}<120 \mathrm{~km} / \mathrm{h}\end{array}$ \\
\hline Grossa & $0,80 \leq \mathrm{HS} \leq 1,20$ & Indicado para vias com V > $120 \mathrm{~km} / \mathrm{h}$ \\
\hline Muito grossa & $\mathrm{HS} \geq 1,20$ & $\begin{array}{l}\text { Indicação em casos especiais, como por exem- } \\
\text { plo: zona com clima muito frio e presença de } \\
\text { gelo na superfície }\end{array}$ \\
\hline
\end{tabular}

No que tange ao ensaio de drenabilidade, tem-se que o equipamento utilizado nesta pesquisa foi disponibilizado pelo LTP-USP, com dimensões baseadas no equipamento do Instituto ETHZ de Zurique, na Suíça, denominado drenômetro (Figura 9). 


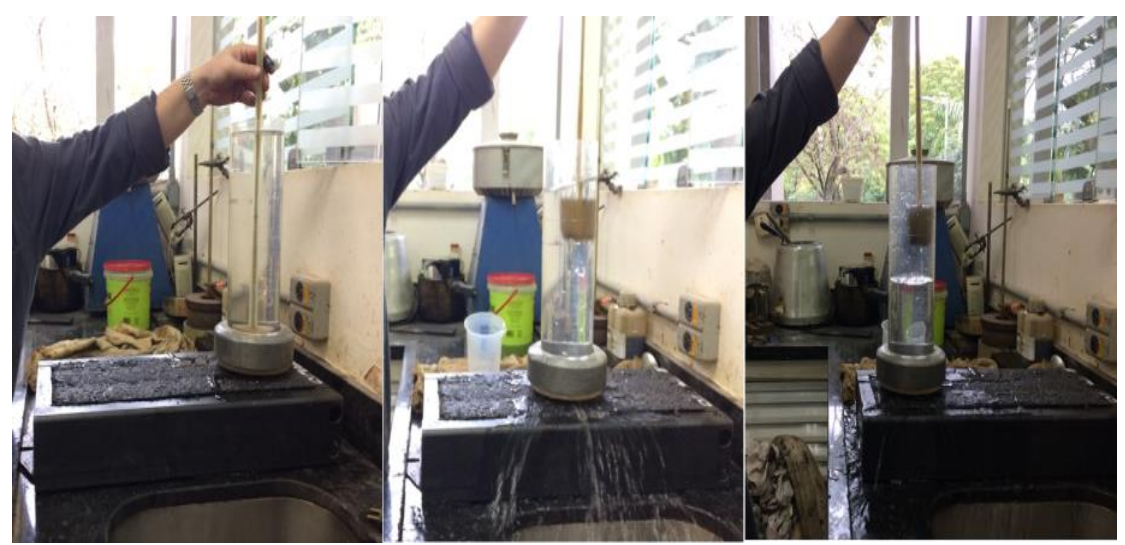

Figura 9: Ensaio de drenabilidade.

Consiste em um cilindro acrílico transparente com aproximadamente $114,3 \mathrm{~mm}$ de diâmetro, contendo duas marcações de nível em sua circunferência, e um orifício circular de 50,0mm de diâmetro posicionado no interior da base de apoio, o qual é vedado com uma rolha antes do início do ensaio, para possibilitar o preenchimento do referido tubo com água até próximo de sua geratriz superior. A base deste cilindro contém ainda um anel de borracha rígida que faz contato direto com a superfície da mistura asfáltica a ser analisada, e um anel metálico, visando conferir estabilidade ao equipamento durante o ensaio e nivelar a superfície de contato. O resultado é tomado com base no tempo gasto para o escoamento do volume de água entre as duas marcas de nível mencionadas.

Não há para este ensaio qualquer parâmetro normativo a ser considerado como ideal, ficando a critério do projetista definir se o tempo de escoamento medido é adequado ou não, levando em conta as características da mistura asfáltica formulada, bem como as condições em que será aplicada no campo, como categoria da via e pluviometria local, por exemplo.

\section{RESULTADOS E DISCUSSÕES}

A partir dos resultados obtidos no ensaio da PCG (Tabela 7; Figura 10), tem-se que as misturas asfálticas CT $4,54 \%, \mathrm{CT} 4,86 \%, \mathrm{CP} 5,50 \%$, CC 5,00 \% e CC 5,50 \%, estão enquadradas no intervalo normativo quanto ao teor de vazios de 4,0 a 9,0\% para misturas asfálticas do tipo BBSG, tomando como referência a leitura em 80 giros [43].

Tabela 7: Resultado do ensaio da PCG.

\begin{tabular}{cccccccccc}
\hline & \multicolumn{6}{c}{ \% DE VAZIOS DAS MISTURAS ASFÁLTICAS } \\
\cline { 2 - 10 } NÚMERO DE GIROS & \multicolumn{3}{c}{ CT } & \multicolumn{5}{c}{ CP } & \multicolumn{5}{c}{ CC } \\
\cline { 2 - 10 } & 4,22 & 4,54 & 4,86 & 4,50 & 5,00 & 5,50 & 4,50 & 5,00 & 5,50 \\
\hline 1 & 24,0 & 23,4 & 22,8 & 27,0 & 24,8 & 23,8 & 25,9 & 24,3 & 24,4 \\
\hline 2 & 22,8 & 21,5 & 20,6 & 25,2 & 23,1 & 21,9 & 24,0 & 22,4 & 22,0 \\
\hline 3 & 21,8 & 20,2 & 19,4 & 24,0 & 21,8 & 20,7 & 22,7 & 21,1 & 20,1 \\
\hline 4 & 21,1 & 19,3 & 18,2 & 22,9 & 20,8 & 19,6 & 21,7 & 20,2 & 19,8 \\
\hline 5 & 20,3 & 18,3 & 17,6 & 22,2 & 20,1 & 19,0 & 20,8 & 19,3 & 18,8 \\
\hline 10 & 18,1 & 16,4 & 15,1 & 19,7 & 17,3 & 16,4 & 18,1 & 16,6 & 16,1 \\
\hline 15 & 16,4 & 14,0 & 13,4 & 18,2 & 16,0 & 14,8 & 16,4 & 15,0 & 14,6 \\
\hline 20 & 15,2 & 13,0 & 12,3 & 17,2 & 14,8 & 13,7 & 15,1 & 13,8 & 13,5 \\
\hline 25 & 14,2 & 12,2 & 11,5 & 16,4 & 14,0 & 12,9 & 14,4 & 12,9 & 12,7 \\
\hline 30 & 13,3 & 11,5 & 10,8 & 15,7 & 13,4 & 12,2 & 13,7 & 12,2 & 11,8 \\
\hline 40 & 12,1 & 10,4 & 9,75 & 14,7 & 12,4 & 11,1 & 12,6 & 11,1 & 11,1 \\
\hline 50 & 11,3 & 9,7 & 8,9 & 14,0 & 11,6 & 10,3 & 11,8 & 10,3 & 10,3 \\
\hline 60 & 10,6 & 9,1 & 8,3 & 13,4 & 11,0 & 9,8 & 11,1 & 9,7 & 9,6 \\
\hline 80 & 9,6 & $\mathbf{8 , 2}$ & $\mathbf{7 , 3}$ & 12,5 & 10,1 & $\mathbf{8 , 8}$ & 10,2 & $\mathbf{8 , 7}$ & $\mathbf{8 , 7}$ \\
\hline 100 & 9,0 & 7,5 & 6,6 & 11,9 & 9,4 & 8,1 & 9,5 & 8,0 & 7,9 \\
\hline
\end{tabular}




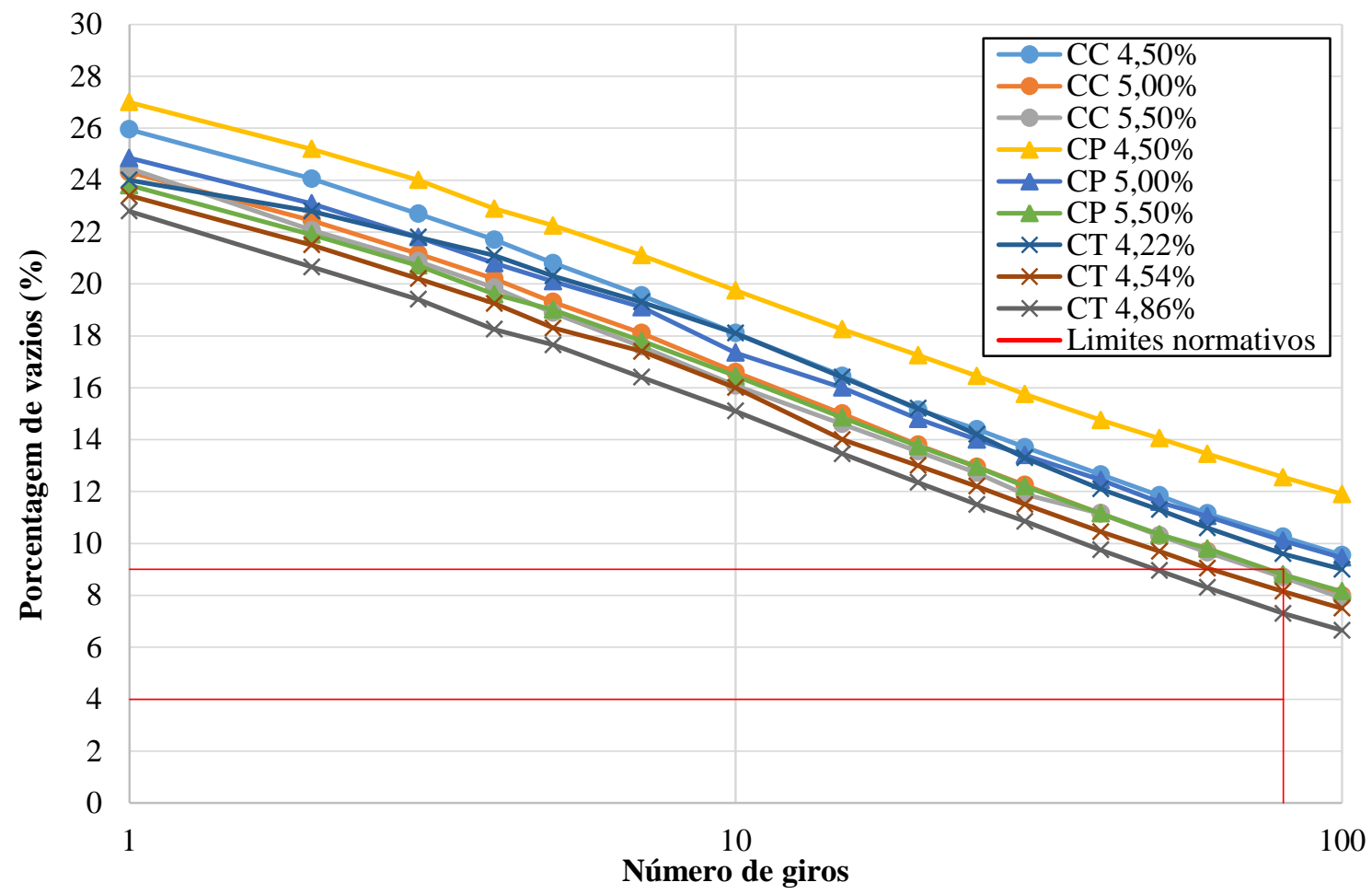

Figura 10: Habilidade de compactação das misturas no ensaio da PCG.

Analisando a Figura 10, é possível observar que as misturas CP necessitaram de maiores teores de ligante para que atingissem a habilidade de compactação desejada, quando comparadas às misturas CT, em razão da maior quantidade de finos presentes em sua composição granulométrica (49\% e 33,3\%, respectivamente), acarretando em maior superfície específica, isto é, maior quantidade de área ocupada por frações granulares a uma dada unidade de peso a ser envolvida pelo ligante betuminoso, $11,15 \mathrm{~m}^{2} / \mathrm{kg}$ (CT) e $15,55 \mathrm{~m}^{2} / \mathrm{kg}(\mathrm{CP})$, de acordo com o critério de DURIEZ [20] apresentado na seção 2.

Cabe destacar que esta situação é fortemente influenciada pela má distribuição de aberturas de peneiras entre os diâmetros $2,2 \mathrm{~mm}$ e $0,075 \mathrm{~mm}$, acarretando uma excessiva concentração de frações heterogêneas no intervalo mencionado (49\%), comprometendo a estabilidade mecânica gerada pelo preenchimento gradual e contínuo dos vazios formados pelas partículas de diâmetros maiores. Este mesmo raciocínio aplica-se às misturas CC quando comparadas às CT, ainda que apresentem um percentual de finos próximo, 28,1\% e 33,3\%, respectivamente.

Ainda assim, o controle granulométrico realizado na CC propiciou melhores desempenhos à habilidade de compactação em relação à $\mathrm{CP}$, pois os percentuais de vazios obtidos a 80 giros em todos os casos foram comparativamente menores, acarretando inclusive na aprovação da dosagem com 5,00\% do teor de ligante, o que não ocorreu para a CP. Tem-se, portanto, que a correção da descontinuidade observada entre as peneiras $9,5 \mathrm{~mm}$ e $2,2 \mathrm{~mm}$, além da melhor distribuição das frações entre as peneiras $2,2 \mathrm{~mm}$ e passante na $0,075 \mathrm{~mm}$, reduzindo o percentual final de finos de $49 \%$ para $28,1 \%$, contribuiu decisivamente para a obtenção de melhores resultados da CC, ainda que tenha sido mantida a mesma série de peneiras da $\mathrm{CP}$.

No caso da CT, tem-se que a forte densificação gerada pela distribuição proporcional e gradual das frações granulares, indicada pelo expoente ' $n$ ' 0,51 da equação (2) de Füller-Talbot e pela trajetória contínua da curva granulométrica, tomando ainda em conta a discretização dos diâmetros de cada abertura das malhas de peneiras isoladamente na composição, acarreta em maior intertravamento entre as partículas, menor formação de volume de vazios internos, e consequentemente, maior habilidade de compactação com menor consumo de ligante betuminoso.

É importante ressaltar que as dosagens não aprovadas no ensaio da PCG foram consideradas rejeitadas, não tendo sido conduzidas à avaliação seguinte quanto à resistência à ação deletéria da água no ensaio de Duriez a $18^{\circ} \mathrm{C}$, conforme preconiza a metodologia francesa [20].

No que diz respeito ao ensaio de Duriez a $18^{\circ} \mathrm{C}$, verificou-se que todas as dosagens selecionadas para esta etapa da pesquisa atenderam à relação mínima $\mathrm{r} / \mathrm{R} \geq 0,70$, especificada para misturas asfálticas densas do tipo BBSG (Figura 11). 


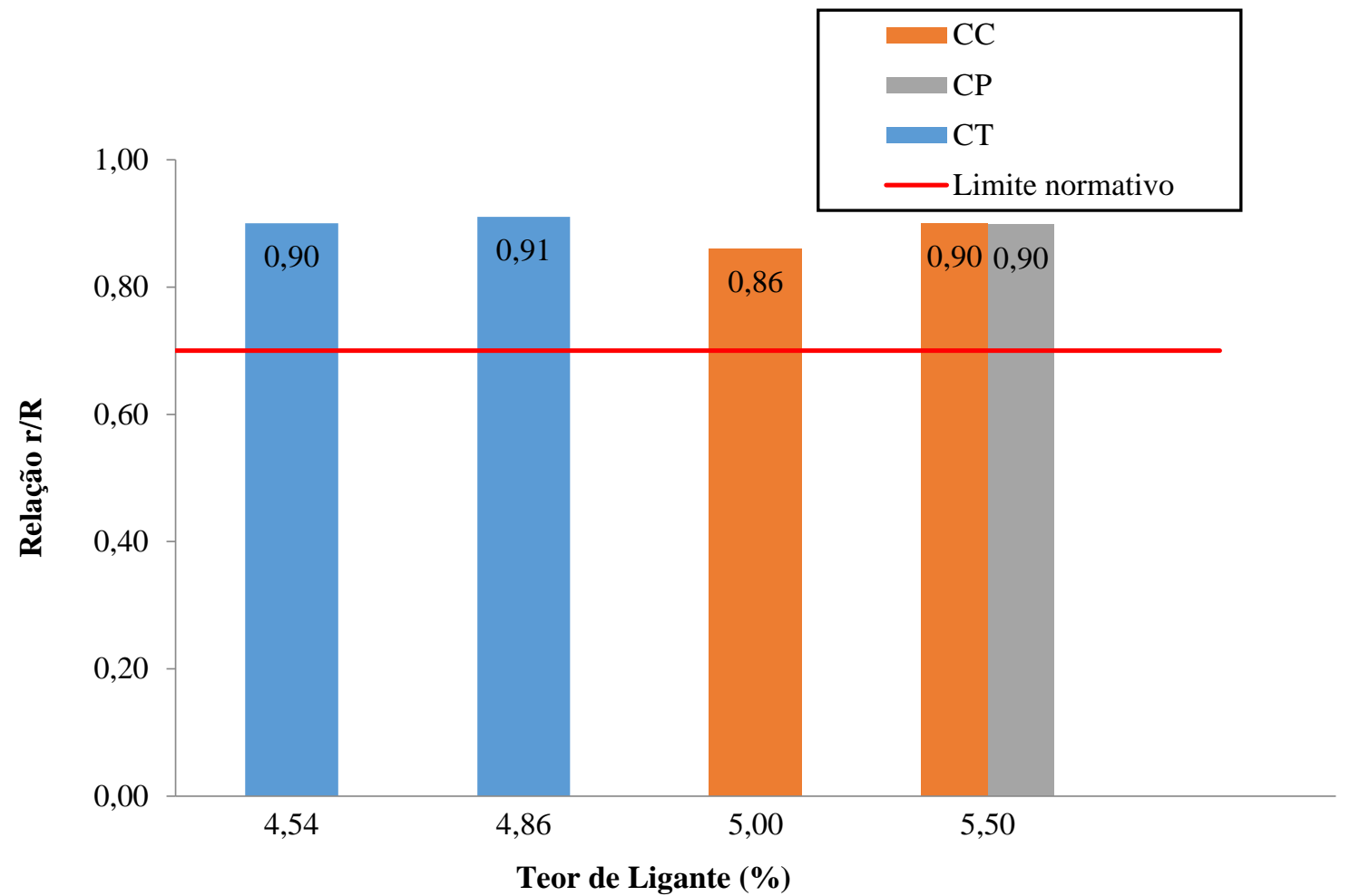

Figura 11: Relação r/R do ensaio de Duriez a $18^{\circ} \mathrm{C}$.

A constatação para que as misturas tenham apresentado bons e próximos valores da relação r/R, deve-se à condição de que todas as formulações testadas possuem característica densa, logo, tendendo à formação de uma grande quantidade de vazios isolados no interior da mistura, ou seja, sem característica comunicante, dificultando a penetração e o respectivo alojamento da água nos seus interstícios. Nestes casos, a ação da tensão superficial da água na interface do conjunto ligante/granular fica mais restrita à parte periférica dos corpos de prova, resultando em uma pequena perda de resistência das misturas.

Entretanto, verificou-se que este ensaio é pouco rigoroso, do ponto de vista da severidade da ação deletéria da água, considerando que o granular gnáissico utilizado na matriz pétrea das misturas possui má adesividade ao ligante betuminoso, além de não ter sido utilizado agente melhorador de adesividade na dosagem. Isto se deve ao fato da temperatura de $18^{\circ} \mathrm{C}$ não ser significativamente intensa no curto período de tempo do ensaio, 7 dias, para que consiga atuar fortemente na modificação da viscosidade do ligante, induzindo mais facilmente a passagem da água para o interior da mistura. Assim, para que houvesse uma ação efetiva da tensão superficial da água superior à tensão interfacial do ligante com o granular, tem-se que o tempo de imersão dos corpos de prova na água deveria ser maior a $18^{\circ} \mathrm{C}$ ou que seja elevada a temperatura de execução do ensaio, por exemplo.

Quanto ao ensaio de resistência à deformação permanente, tem-se que as dosagens testadas nesta etapa foram apenas aquelas aprovadas no conjunto dos ensaios de PCG e de Duriez a $18^{\circ} \mathrm{C}$. A Tabela 8 e a Figura 12 compilam e ilustram, nesta ordem, os resultados obtidos após 30000 ciclos de solicitação. 
Tabela 8: Afundamento na trilha de roda após 30000 ciclos.

\begin{tabular}{cccc}
\hline $\begin{array}{c}\text { Mistura } \\
\text { asfáltica }\end{array}$ & $\begin{array}{c}\text { Teor de ligante } \\
(\%)\end{array}$ & Afundamento (\%) & $\begin{array}{c}\text { Média do } \\
\text { afundamento (\%) }\end{array}$ \\
\hline \multirow{2}{*}{ CT } & 4,54 & $\begin{array}{l}\text { Placa 1: 0,97 } \\
\text { Placa 2: 1,40 }\end{array}$ & 1,19 \\
\cline { 3 - 3 } & 4,86 & $\begin{array}{l}\text { Placa 1: 1,67 } \\
\text { Placa 2: 1,78 }\end{array}$ & 1,73 \\
\hline \multirow{2}{*}{ CC } & 5,00 & $\begin{array}{l}\text { Placa 1: 5,62 } \\
\text { Placa 2: 4,48 }\end{array}$ & 5,05 \\
\cline { 2 - 3 } & 5,50 & $\begin{array}{l}\text { Placa 1: 5,90 } \\
\text { Placa 2: 5,10 }\end{array}$ & 5,50 \\
\hline CP & 5,50 & $\begin{array}{r}\text { Placa 1: 6,45 } \\
\text { Placa 2: 7,75 }\end{array}$ & 7,10 \\
\hline
\end{tabular}

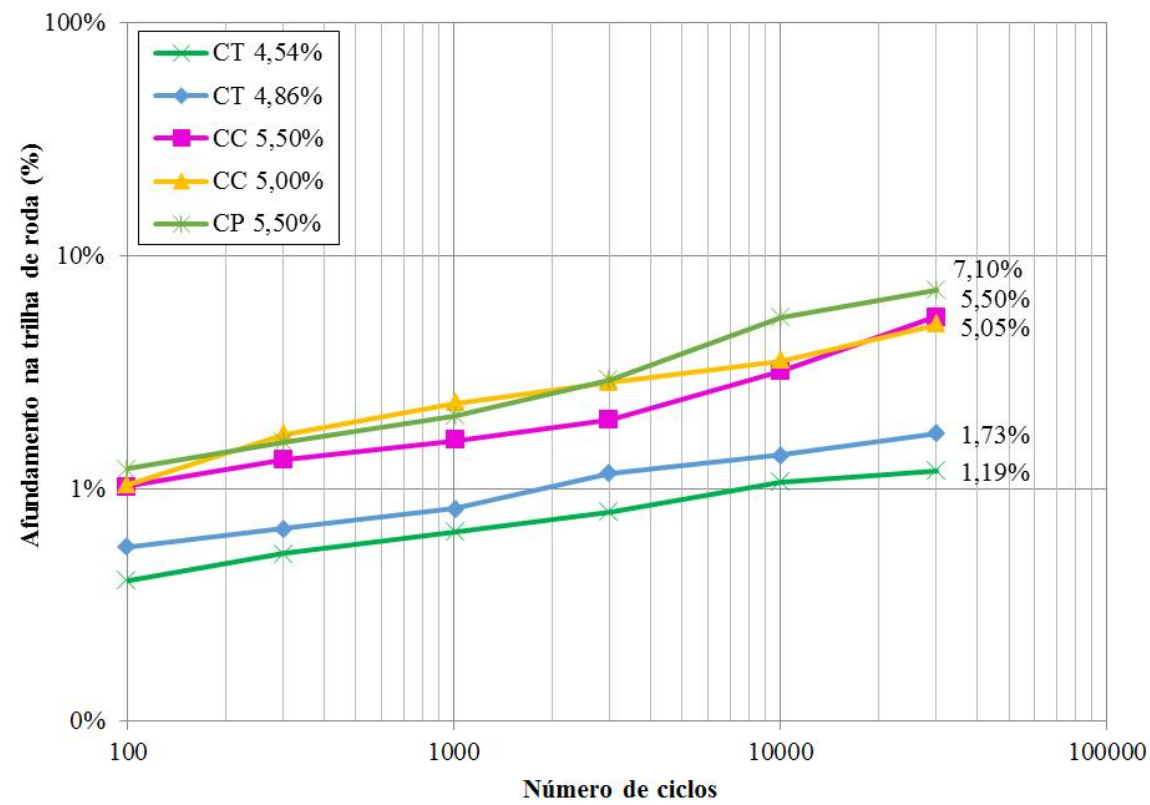

Figura 12: Afundamento na trilha de roda das misturas asfálticas.

Os resultados apresentados demonstram que a CT possui melhor resistência ao afundamento na trilha de roda entre todas as misturas testadas, e que a CPA apresentou melhor resultado que a $\mathrm{CP}$, sendo possível perceber estas condições na observação das placas testadas na Figura 13. 


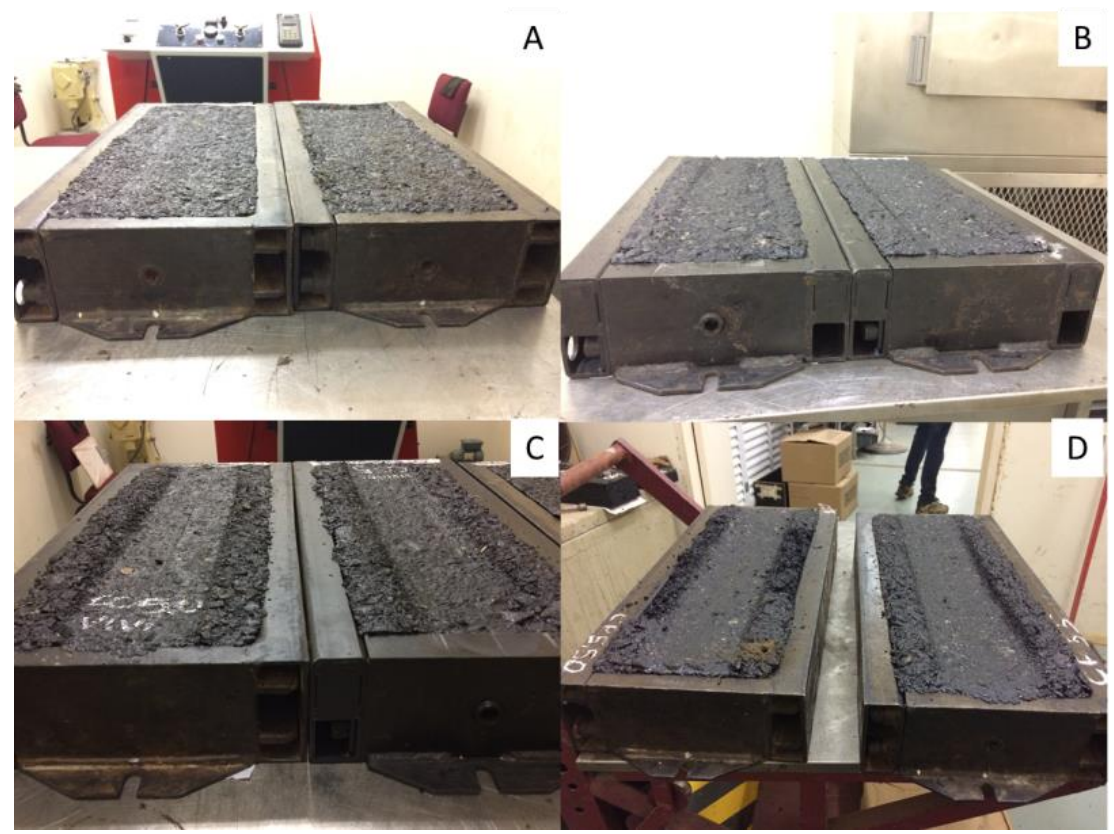

Figura 13: Par de placas (a) antes e; (b) CT, (c) CC, e (d) CP após os ensaios de deformação permanente.

Analogamente à interpretação dos resultados da PCG, porém, analisando as condições para a ocorrência do fenômeno da fluência da mistura asfáltica, que rege a resistência ao afundamento na trilha de roda, tem-se que como a $\mathrm{CP}$ e a CC possuem maior superfície especifica que a CT, acarretando na maior presença de finos abaixo da peneira 2,2mm nas curvas granulométricas, consequentemente, maior percentual de ligante betuminoso será necessário para compor as suas dosagens, conforme se verifica na Tabela 8.

Some-se a estes fatores a já citada e demonstrada má distribuição das frações granulares nas curvas $\mathrm{CP}$ e CC entre as peneiras $2,2 \mathrm{~mm}$ e $0,075 \mathrm{~mm}$, ocasionada pela pouca presença de peneiras existente neste intervalo.

Neste contexto, menor será a estabilidade mecânica das misturas asfálticas CP e CC quanto a resistir aos esforços de cisalhamento aplicados pela passagem da carga dinâmica do eixo da máquina de deformação permanente à baixa frequência $(1 \mathrm{~Hz})$ e elevada temperatura $\left(60^{\circ} \mathrm{C}\right)$, ocasionando maior suscetibilidade à ocorrência do fenômeno de fluência no material, quando comparadas às misturas CT, que apresentam condições opostas de concepção, logo, mais adequadas.

Ainda assim, observando a Figura 11, verifica-se que as misturas CC, devido ao ajuste granulométrico a que foram submetidas pelo método controlado, apresentaram melhores resultados que a $\mathrm{CP}$, em que pese ambas terem sido enquadradas na classe 2 das misturas do tipo BBSG.

Esta condição se explica, em razão das misturas CC terem alcançado percentuais de afundamento na trilha de roda não muito distantes do valor máximo admissível para a classe $3(5,00 \%)$, que é a mais nobre para a aplicação em campo das misturas do tipo BBSG, principalmente a CC 5,00\%. Em contrapartida, a CP $5,50 \%$ obteve percentual de afundamento 7,10\%, ou seja, próximo ao limite mínimo previsto para a classe 1 $(7,50 \%)$, isto é, a de menor qualificação entre as misturas BBSG. No caso das misturas CT, todas demonstraram a melhor resistência à deformação permanente, em razão dos percentuais alcançados terem sido bem abaixo do limite de 5,00\%, posicionando-as na classe 3 , a mais nobre.

Para as análises da rugosidade superficial a partir da medição da altura da mancha de areia, de acordo com a classificação proposta por PASQUET [49] (Tabela 6), tem-se que as misturas asfálticas desta pesquisa estão enquadradas na textura superficial considerada grossa, em função dos resultados obtidos terem compreendido um intervalo entre $0,80 \mathrm{~mm}$ e $1,20 \mathrm{~mm}$ (Figura 14). Isto significa que estão aptas à aplicação em pavimentos sujeitos a velocidades acima de $120 \mathrm{~km} / \mathrm{h}$. 


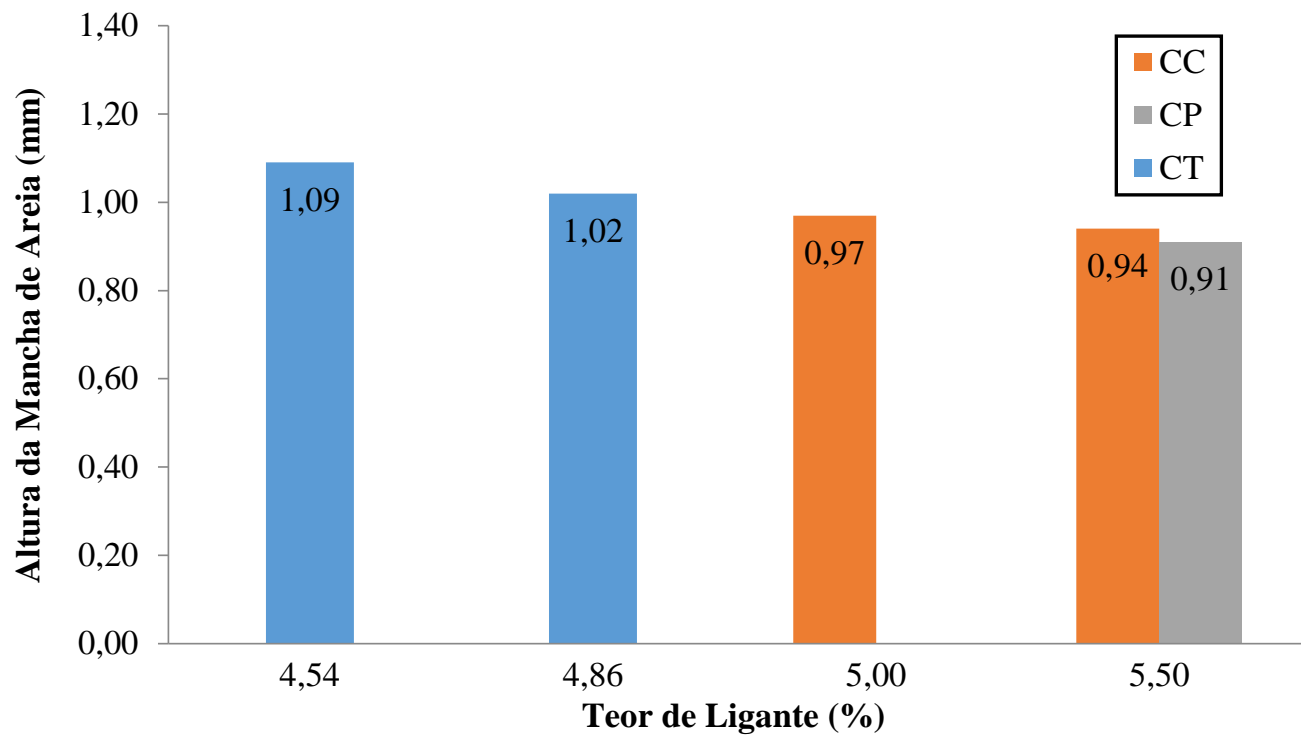

Figura 14: Rugosidade da superfície das placas de misturas asfálticas pela altura da mancha de areia.

Os resultados referentes à textura superficial se mostraram coerentes, pois quanto menores foram as dosagens de ligante, maiores foram os valores de altura da mancha de areia obtidos, indicando que quanto menor a participação de ligante betuminoso na composição das misturas asfálticas, maior tende a ser formação dos canais de curtose superficiais gerados na superfície entre os granulares, aumentando a rugosidade.

Contudo, é importante esclarecer que apesar de todas as misturas asfálticas estarem habilitadas macrotexturalmente para utilização em tráfegos com velocidade superior a $120 \mathrm{~km} / \mathrm{h}$, deve-se observar que apenas as misturas CT obtiveram resultados enquadrados na classe 3 do ensaio de deformação permanente, ou seja, que as permite serem utilizadas em rodovias ou vias urbanas com tráfego elevado, canalizado e intenso, enquanto as misturas CP e CC estão situadas na classe 2, que apesar de conferí-las possibilidade de aplicação em regiões com forte gradiente térmico, devem ser submetidas a tráfegos menos intensos que na classe 3 , até mesmo pelos limites normativos mais tolerantes que admitem de afundamento na trilha de roda.

No caso dos ensaios de drenabilidade, tem-se que os tempos medidos (Tabela 9), em geral, são curtos o suficiente para que se evitem zonas de acumulação de água na superfície dos pavimentos, mesmo em condições de tráfegos com elevada frequência de solicitação, garantindo segurança ao usuário quanto a não ocorrência de hidroplanagem e do efeito spray durante o contato pneu-pavimento, desde que sejam projetados e executados com rigor técnico os abaulamentos ou as declividades transversais que permitam a viabilidade deste cenário em campo.

Tabela 9: Tempo de escoamento superficial da água no ensaio de drenabilidade.

\begin{tabular}{ccc}
\hline Mistura asfáltica & Teor de ligante & Drenabilidade (tempo de escoamento superficial) \\
\hline \multirow{2}{*}{ CT } & $4,54 \%$ & 3 "07 \\
& $4,86 \%$ & 3 "08 \\
\hline \multirow{2}{*}{ CC } & $5,00 \%$ & $3 " 10$ \\
& $5,50 \%$ & $3 " 48$ \\
\hline $\mathrm{CP}$ & $5,50 \%$ & $3 " 55$ \\
\hline
\end{tabular}

É possível, portanto, constatar que os resultados de drenabilidade corroboram as tendências apresentadas nos ensaios de mancha de areia, pois quanto maior a textura superficial das misturas asfálticas, menor foi o tempo de escoamento da água na superfície das placas testadas, em razão da diminuição dos canais de curtose superficiais gerados entre os granulares, diminuindo a rugosidade superficial.

Há que se destacar também o caráter empírico dos ensaios de mancha de areia e de drenabilidade, devendo ser considerados mais como indicadores qualitativos do que quantitativos, porém, de grande praticidade e valia em análises de rugosidades superficiais de misturas asfálticas, tanto em campo quanto em laboratório, pois os resultados são obtidos diretamente sobre os próprios materiais produzidos, sem uso de qualquer fator de correlação. 


\section{CONCLUSÕES}

A partir da campanha experimental realizada, tem-se que os resultados obtidos demonstram e comprovam ser a composição granulométrica, notadamente o método de formulação utilizado, uma variável decisiva na concepção de misturas asfálticas capazes de apresentarem bom comportamento mecânico, sobretudo no que diz respeito à habilidade de compactação, resistência à ação deletéria da água e à deformação permanente, bem como funcional, no que tange à textura e drenabilidade superficiais.

Neste contexto, verifica-se que o método teórico racional de Füller-Talbot, utilizado na formulação da mistura CT, mostrou-se mais eficiente que as modalidades por tentativa (CP) e controlada (CC), devido permitir melhor distribuição proporcional das frações granulares, destacando a discretização do peneiramento isolado de cada diâmetro de partícula, compreendendo ainda uma sequência com maior número de peneiras, propiciando os melhores indicadores mecânicos e funcionais durante a campanha experimental realizada. Estas tendências são corroboradas por outros trabalhos [50- 55].

Entretanto, cabe destacar que o método controlado, ao corrigir as descontinuidades apresentadas pela curva formulada por tentativa, e considerar também o peneiramento de cada diâmetro de partícula de forma isolada para a composição da curva granulométrica, caso da mistura $\mathrm{CC}$, propiciou melhores resultados quando comparados à mistura $\mathrm{CP}$, mesmo ainda considerando a mesma série má distribuída de aberturas de malhas de peneiras, em razão do método por tentativa utilizar-se de composições heterogêneas das frações comerciais, dificultando o controle da distribuição percentual pelo projetista, não raro gerando descontinuidades na trajetória da curva granulométrica, acarretando os piores resultados obtidos entre todas as misturas asfálticas testadas.

Logo, é possível concluir que a metodologia de formulação por tentativa adotada correntemente pelos órgãos rodoviários no Brasil, baseada no uso de faixas limítrofes, deve ser substituída por procedimentos normativos mais acurados, que permitam ao projetista controle absoluto da distribuição percentual das frações granulométricas, sem descontinuidades na trajetória das curvas, bem como a adição de maior número de aberturas de malhas de peneiras nas séries sequenciais, à razão de metade do diâmetro imediatamente superior, sobretudo nas malhas mais finas.

Ainda, estas medidas não exigem necessidade de aportes tecnológicos de elevada monta financeira para que sejam viabilizadas na prática, apenas adaptações pontuais nas centrais de peneiramento dos granulares e de usinagem das misturas asfálticas. Para tanto, deve ser inserido um número maior de malhas nos decks de peneiramento das pedreiras, que permita selecionar os granulares em frações discretizadas e, que sejam correspondentes às aberturas especificadas no projeto da curva granulométrica em cada caso. De igual forma, é necessário o aporte de maior quantidade de silos frios nas estruturas das usinas, a fim de que possam comportar o armazenamento e alimentação controlada de todas as frações individuais obtidas nos processos de peneiramento.

Estes fatores possibilitarão condições de melhor preenchimento gradual dos vazios formados pelos granulares de maior dimensão, propiciando melhor intertravamento entre as partículas, com menor consumo de ligante betuminoso, e consequentemente, melhor resistência aos esforços cisalhantes em situações críticas de elevada temperatura e baixa frequência de solicitação, que contribuem na ocorrência do fenômeno de fluência das mistura asfálticas, conforme observado nos ensaios de deformação permanente. Outrossim, corrobora os melhores indicadores funcionais de textura superficial e drenabilidade, garantindo condições adequadas de aderência na superfície de contato pneu-pavimento, evitando a ocorrência do fenômeno da hidroplanagem e do efeito spray, atendendo, de fato, aos parâmetros de conforto, segurança e economia de custos aos usuários, com utilização adequada do erário público.

\section{AGRADECIMENTOS}

Ao Conselho Nacional de Desenvolvimento Científico e Tecnológico (CNPq) pela concessão da bolsa de estudos à Viviane Dias Andrade durante a realização de sua pesquisa de Mestrado, bem como à Prof ${ }^{a}$. Liedi Bernucci, pela participação ativa no acompanhamento da pesquisa e cessão das instalações do Laboratório de Técnicas em Pavimentação (LTP) da USP, possibilitando a realização de grande parte da campanha experimental.

\section{BIBLIOGRAFIA}

[1] MORILHA, A.J., Estudo sobre a ação de modificadores no envelhecimento dos ligantes asfálticos e nas propriedades mecânicas e de fadiga das misturas asfálticas. Dissertação de Mestrado apresentada ao Progra- 
ma de Pós-Graduação em Engenharia Civil (PPGEC) da Universidade Federal de Santa Catarina (UFSC), Florianópolis, SC, Brasil, p.185, 2004.

[2] BARRA, B.S., Avaliação da ação da água no módulo complexo e na fadiga de misturas asfálticas densas. Tese de Doutorado apresentada ao Programa de Pós-graduação em Engenharia Civil (PPGEC) da Universidade Federal de Santa Catarina (UFSC). Florianópolis, SC, Brasil, p. 329, 2009.

[3] SOUZA, N.S.L., ANJOS, M.A.S., SÁ, M.V.V.A. et al., "Development of lightweight aggregates from crushing of ornamental stones (granites and marbles) and clay". Matéria (Rio J.), vol. 25, $\mathrm{n}^{\circ} 1$. Rio de Janeiro, 2020. DOI: https://doi.org/10.1590/s1517-707620200001.0884.

[4] XAVIER, M.F.; FERREIRA, W.L.G.; CASTELO BRANCO, V.T.F. "Avaliação do uso de cinzas de carvão mineral como melhorador de adesividade em misturas asfálticas". Matéria (Rio J.), vol. 25, no 1 . Rio de Janeiro 2020. DOI: http://dx.doi.org/10.1590/s1517-707620200001.0891.

[5] CUNHA, C.B., BUDNY, J., KLAMT, R.A., et al., "Avaliação de concreto asfáltico usinado a quente com incorporação de material fresado". Matéria (Rio J.), DOI: https://doi.org/10.1590/s1517707620180003.0520, v. 23, n. 3, Rio de Janeiro 2018.

[6] CUNHA, M.A.J., SILVA, C.L., LIMA, C.A.P., et al., "Efeito da temperatura no comportamento mecânico de misturas asfálticas com agregados sinterizados de argila calcinada (ASAC)". Matéria (Rio J.), DOI: https://doi.org/10.1590/s1517-707620170001.0306. v. 23, n. 1. Rio de Janeiro, 2018.

[7] ANDRADE, V.D., Influência da formulação de esqueletos minerais na deformação permanente de misturas de concreto asfáltico densas. Dissertação de Mestrado apresentada ao Programa de Pós-Graduação em Engenharias e Ciências Mecânicas (Pós-ECM) da Universidade Federal de Santa Catarina (UFSC), Joinville, SC, Brasil, p. 167, 2018.

[8] BURIGO, A.S., BARRA, B.S., MOMM, L., et al., "Influencia de la Formulación de Esqueletos Minerales en el Comportamiento Mecánico de Mezclas Asfálticas". In: XVIII Congreso Iberolatinoamericano del Asfalto - CILA, Bariloche, Argentina, v. único, pp. 730-741, Noviembre 2015.

[9] FERREIRA, J.L.S., BASTOS, J.B.S., SOARES, J.B., "Validação da metodologia de faixa de agregados dominantes para validação e especificação da granulometria de misturas asfálticas densas". In: XXIX Congresso Nacional de Pesquisa em Transporte da ANPET, Ouro Preto, MG, vol. Único, pp. 85-96, Novembro 2015.

[10] AHLRICH, R., "Influence of Aggregate Properties on Performance of Heavy-Duty Hot-Mix Asphalt Pavements". Transportation Research Record: Journal of the Transportation Research Board, DOI: 10.3141/1547-02, v. 1547, n. 1, pp.7-14, January 1996.

[11] MOMM, L., Estudo dos efeitos da granulometria sobre a macrotextura superficial do concreto asfáltico e seu comportamento mecânico. Tese de Doutorado apresentada ao Programa de Engenharia de Transportes (PTR) da Escola Politécnica da Universidade de São Paulo (USP). São Paulo, SP, Brasil, p. 289, 1998.

[12] BAHIA, H.U., STAKSTON, A., The effect of fine aggregate angularity, asphalt content and performance graded asphalts on hot mix asphalt performance. University of Wisconsin-Madison, Department of Civil and Environmental Engineering, p. 155, 2003.

[13] WERKMEISTER, S. Permanent deformation behavior of unbound granular materials in pavement constructions. PhD Thesis presented to the Post-Graduation Program in Civil Engineering of the Technischen Universität Dresden. Dresden, Germany, p. 189, 2003.

[14] PÉREZ, I., MEDINA, L., ROMANA, M.G., "Permanent deformation models for a granular material used in road pavements". Construction and Building Materials Journal, DOI: 10.1016/j.conbuildmat.2005.01.050, v. 20, n. 9, pp.790-800, November 2006.

[15] TUTUMLUER, E., PAN, T., "Aggregate morphology affecting strength and permanent deformation behavior of unbound aggregate materials". Journal Of Materials In Civil Engineering, DOI: 10.1061/(asce)0899-1561(2008)20:9(617), v. 20, n. 9, pp.617-627, September 2008.

[16] GUIMARÃES, A.C.R., Um método mecanístico-empírico para a previsão da deformação permanente em solos tropicais constituintes de pavimentos. Tese de Doutorado apresentada ao Programa de Engenharia Civil Universidade Federal do Rio de Janeiro (UFRJ), Rio de Janeiro, RJ, p. 367,2009.

[17] GOLALIPOUR, A., JAMSHIDI, E., NIAZI, Y., et al., "Effect of Aggregate Gradation on Rutting of Asphalt Pavements". Procedia - Social And Behavioral Sciences, DOI: 10.1016/j.sbspro.2012.09.895.v. 53, pp.440-449, October 2012. 
[18] ACIKGÖZ, O., RAUF, R., Analysis of parameters affecting permanent deformation in road pavement. Master's Dissertation presented to the Post-Graduation Program on Road and Traffic from Department of Civil And Environmental Engineering, Chalmers University Of Technology, Göteborg, Suécia, p. 113, 2010.

[19] LIMA, C.D.A. Estudo da deformação permanente de duas britas graduadas para uso em camadas de pavimentos. Dissertação de Mestrado apresentada ao Programa de Engenharia Civil da Universidade Federal do Rio de Janeiro (UFRJ). P. 268, Rio de Janeiro, RJ, 2016.

[20] MANUEL LPC., Manuel LPC d'aide à la formulation des enrobés. Groupe de Travail RS. "Formulation des enrobés". 199 p. Laboratoire Central des Ponts et Chaussées. Paris, France, 2017.

[21] DNER-ME 35/98, Agregados - determinação da abrasão "Los Angeles". Departamento Nacional de Infraestrutura de Transportes (DNIT). http://ipr.dnit.gov.br/normas-e-manuais/normas/meetodo-de-ensaiome/metodo-de-ensaio-me. Acessado em fevereiro de 2020.

[22] DNER-EM 37/97, Agregado graúdo para concreto de cimento. Departamento Nacional de Infraestrutura de Transportes (DNIT). http://ipr.dnit.gov.br/normas-e-manuais/normas/especificacao-de-materialem/especificacao-de-material-em. Acessado em fevereiro de 2020.

[23] DNER-ME 89/94, Agregados - avaliação da durabilidade pelo emprego de soluções de sulfato de sódio ou de magnésio. Departamento Nacional de Infraestrutura de Transportes (DNIT).

http://ipr.dnit.gov.br/normas-e-manuais/normas/meetodo-de-ensaio-me/metodo-de-ensaio-me. Acessado em fevereiro de 2020.

[24] ABNT NBR 7809/2006, Agregado graúdo - Determinação do índice de forma pelo método do paquímetro - Método de ensaio. https://www.abntcatalogo.com.br/norma.aspx?ID=79835. Acessado em fevereiro de 2020.

[25] DNER-ME 78/94, Agregado graúdo - adesividade a ligante betuminoso. Departamento Nacional de Infraestrutura de Transportes (DNIT). http://ipr.dnit.gov.br/normas-e-manuais/normas/meetodo-de-ensaiome/metodo-de-ensaio-me. Acessado em fevereiro de 2020.

[26] DNER-ME 54/97, Equivalente de areia. Departamento Nacional de Infraestrutura de Transportes (DNIT). http://ipr.dnit.gov.br/normas-e-manuais/normas/meetodo-de-ensaio-me/metodo-de-ensaio-me. Acessado em fevereiro de 2020 .

[27] DNER-ME 266/97, Agregados - determinação do teor de materiais pulverulentos. Departamento Nacional de Infraestrutura de Transportes (DNIT). http://ipr.dnit.gov.br/normas-e-manuais/normas/meetodo-deensaio-me/metodo-de-ensaio-me. Acessado em fevereiro de 2020.

[28] DNIT-ME 155/2010, Material asfáltico - Determinação da penetração. Departamento Nacional de Infraestrutura de Transportes (DNIT). http://ipr.dnit.gov.br/normas-e-manuais/normas/meetodo-de-ensaiome/metodo-de-ensaio-me. Acessado em fevereiro de 2020.

[29] DNIT-ME 131/2010, Materiais asfálticos - Determinação do ponto de amolecimento - Método do Anel e Bola. Departamento Nacional de Infraestrutura de Transportes (DNIT). http://ipr.dnit.gov.br/normas-emanuais/normas/meetodo-de-ensaio-me/metodo-de-ensaio-me. Acessado em fevereiro de 2020.

[30] ANP No 19/2005, Especificações de Produtos Derivados de Petróleo. Agência Nacional do Petróleo. http://legislacao.anp.gov.br/?path=legislacao-anp/resol-anp/2015/abril\&item=ranp-19-2015. Acessado em fevereiro de 2020.

[31] ABNT NBR 14950/2003, Materiais betuminosos - Determinação da viscosidade Saybolt Furol. Materiais betuminosos. https://www.abntcatalogo.com.br/norma.aspx?ID=001891. Acessado em fevereiro de 2020 .

[32] ABNT NBR 6296/2012, Produtos betuminosos semissólidos - Determinação da massa específica e densidade relativa. https://www.abntcatalogo.com.br/norma.aspx?ID=193521. Acessado em fevereiro de 2020.

[33] SIROMA, R.S., Avaliação da deformação permanente em misturas asfálticas densas formuladas com areia descartada de fundição (ADF). Dissertação de Mestrado apresentada ao Programa de Pós-Graduação em Engenharia e Ciências Mecânicas (Pós-ECM) da Universidade Federal de Santa Catarina (UFSC), Joinville, SC, Brasil, p. 196, 2018.

[34] LEITE, L.F.M., MENEZES, S.M.C., Efeito da composição química dos ligantes na resistência ao descolamento de misturas asfálticas. In: XVII Congresso Nacional de Pesquisa em Transporte da ANPET, CDROM, Rio de Janeiro, RJ, Novembro 2003.

[35] DNIT, Manual de Pavimentação. Departamento Nacional de Infraestrutura de Transportes. http://www1.dnit.gov.br/arquivos_internet/ipr/ipr_new/manuais/Manual\%20de\%20Pavimenta\%E7\%E3o_05. 12.06.pdf, 2006. Acessado em fevereiro de 2020. 
[36] DER/PR - ES-P-15/05, Pavimentação: Concreto asfáltico usinado a quente com asfalto polímero. Departamento de Estradas de Rodagem do Estado do Paraná.

http://www.der.pr.gov.br/arquivos/File/PDF/pdf_Pavimentacao/ES-P15-05CAUQcomAsfaltoPolimero.pdf, 2005. Acessado em fevereiro de 2020.

[37] DNIT-ES 031/2006, Pavimentos Flexíveis - Concreto Asfáltico. Departamento Nacional de Infraestrutura de Transportes. http://ipr.dnit.gov.br/normas-e-manuais/normas/especificacao-de-servicoses/dnit031_2006_es.pdf, 2006. Acessado em fevereiro de 2020.

[38] GUIDE TECHNIQUE, French Design Manual for Pavement Structures - Guide Technique (English Version). Published by Service d'Études Techniques des Routes et Autoroutes (SETRA) and Laboratoire Central des Ponts et Chaussées (LCPC), 248 p, 1998.

[39] LIRA, B., EKBLAD, J., LUNDSTRÖM, R., Evaluation of asphalt rutting based on mixture aggregate gradation. Journal Road Materials and Pavement Design (RMPD), DOI:

https://doi.org/10.1080/14680629.2019.1683061, p. 18, Oct. 2019,

[40] SOHM, J., Prédictions des déformations permanentes des matériaux de chaussées. Thèse de Doctorat soumise à l'École Centrale de Nantes (ECN), Nantes, France, p. 301, 2011

[41] MONISMITH, C.L., Rutting prediction in asphalt concrete pavements, In: 55th Annual Meeting of the Transportation Research Board, Washington, USA, Available at http://onlinepubs.trb.org/onlinepubs/trr/1976/616/616-001.pdf, pp. 2-8, Jan. 1976.

[42] ABNT NBR 15619/2012, Misturas asfálticas - Determinação da densidade máxima teórica e da massa específica máxima teórica em amostras não compactadas.

https://www.abntcatalogo.com.br/norma.aspx?ID=091564. Acessado em fevereiro de 2020.

[43] AFNOR NF EN 12697-31, Mélanges bitumineux - Méthodes d'essai - Partie 31 : Confection d'éprouvettes à la presse à compactage giratoire (PCG). Association Française de Normalisation. Paris, France, 2007.

[44] AFNOR NF EN 12697-12, Mélanges bitumineux - Méthodes d'essai - Partie 12 : Détermination de la sensibilité à l'eau des éprouvettes bitumineuses. Association Française de Normalisation. Paris, France, 2008.

[45] AFNOR NF EN 12697-22, Mélanges bitumineux - Méthodes d'essai - Partie 22 : Essai d'orniérage. Association Française de Normalisation. Paris, France, 2007.

[46] BARRA, B.S., MOMM, L., BROSSEAUD, Y., et al., Diretrizes para a Formulação e Avaliação do Comportamento Mecânico de Misturas Asfálticas. Revista Pavimentação, v. 17, p. 38-58, 2010.

[47] AFNOR NF EN 13036-1, Caractéristiques de surface des routes et aérodromes - Méthodes d'essai - Partie 1: mesurage de la profondeur de macrotexture de la surface d'un revêtement à l'aide d'une technique volumétrique à la tâche de sable. Association Française de Normalisation. Paris, France, 2010.

[48] AFNOR NF EN 13036-3, Caractéristique de surface de routes et aérodromes - méthodes d'essai - partie 3: méthodes d'essai pour mesurer la drainabilité superficielle d'un revêtement de chaussée. Association Française de Normalisation. Paris, France, 2002.

[49] PASQUET, A., Campagne Nationale de Glissance 1967 en France, In: Colloque International sur la Glissance et la Sécurité de la Circulation sur Routes Mouillées, Berlin, Germany, pp. 717-732, 1968.

[50] ALMEIDA JR, P.O.B.; BOEIRA, F.D., SPECHT, L.P., et al., "Avaliação laboratorial do tipo e teor de ligante e da granulometria na deformação permanente de misturas asfálticas". Revista Transportes, DOI: https://doi.org/10.14295/transportes.v26i2.1407. , v. 26, n. 2, 15 p., 2018.

[51] MOURA, E. Estudo da deformação permanente em trilha de roda em campo e laboratório. Tese de Doutorado. Tese de Doutorado apresentada ao Programa de Engenharia de Transportes (PTR) da Escola Politécnica da Universidade de São Paulo (USP). São Paulo, SP, Brasil, 299 p., 2010.

[52] BARRA, B. Avaliação do desempenho mecânico de misturas asfálticas densas utilizando materiais do Estado do Pará com o emprego de pó calcário. Dissertação de Mestrado apresentada ao Programa de PósGraduação em Engenharia Civil (PPGEC) da Universidade Federal de Santa Catarina (UFSC). Florianópolis, SC, Brasil, p. 177, 2005.

[53] CARVALHO, A.D. Propriedades das Misturas Asfálticas Densas com Brita e com Seixo Rolado Utilizadas como Revestimento de Pavimentos no Pará. Dissertação de Mestrado apresentada ao Programa de Engenharia de Transportes (PTR) da Escola Politécnica da Universidade de São Paulo (USP). São Paulo, SP, Brasil, p. 299, 1999. 
[54] LV, Q., HUANG, W., ZHENG, M., et al., "Influence of gradation on asphalt mix rutting resistance measured by Hamburg Wheel Tracking test". Construction and Building Materials Journal, DOI: https://doi.org/10.1016/j.conbuildmat.2019.117674., v. 238, p. 117674, March 2006.

[55] CAI, X., WU, K.H., et al., Study on the correlation between aggregate skeleton characteristics and rutting performance of asphalt mixture. Construction and Building Materials Journal, DOI: https://doi.org/10.1016/j.conbuildmat.2018.05.153, v. 179, pp. 294-301, August 2018.

\section{ORCID}

Viviane Dias Andrade

https://orcid.org/0000-0002-7851-4672

Breno Barra

https://orcid.org/0000-0003-2212-8163

Liedi Bernucci

https://orcid.org/0000-0002-4768-0993

Leto Momm

https://orcid.org/0000-0003-0243-7903

Yader Guerrero Pérez

https://orcid.org/0000-0002-4048-050X

Daniel Hastenpflug

https://orcid.org/0000-0002-8469-5756

Helena Nierwinski

https://orcid.org/0000-0002-6286-2250

Marcelo Heidemann

https://orcid.org/0000-0002-4528-6132 